\title{
The Use and Abuse of Heme in Apicomplexan Parasites
}

\author{
Giel G. van Dooren, Alexander T. Kennedy, ${ }^{2}$ and Geoffrey I. McFadden ${ }^{2}$
}

\begin{abstract}
Significance: Heme is an essential prosthetic group for most life on Earth. It functions in numerous cellular redox reactions, including in antioxidant defenses and at several stages of the electron transport chain in prokaryotes and eukaryotic mitochondria. Heme also functions as a sensor and transport molecule for gases such as oxygen. Heme is a complex organic molecule and can only be synthesized through a multienzyme pathway from simpler precursors. Most free-living organisms synthesize their own heme by a broadly conserved metabolic pathway. Parasites are adept at scavenging molecules from their hosts, and heme is no exception. Recent Advances: In this review we examine recent advances in understanding heme usage and acquisition in Apicomplexa, a group of parasites that include the causative agents of malaria, toxoplasmosis, and several major parasites of livestock. Critical Issues: Heme is critical to the survival of Apicomplexa, although the functions of heme in these organisms remain poorly understood. Some Apicomplexa likely scavenge heme from their host organisms, while others retain the ability to synthesize heme. Surprisingly, some Apicomplexa may be able to both synthesize and scavenge heme. Several Apicomplexa live in intracellular environments that contain high levels of heme. Since heme is toxic at high concentrations, parasites must carefully regulate intracellular heme levels and develop mechanisms to detoxify excess heme. Indeed, drugs interfering with heme detoxification serve as major antimalarials. Future Directions: Understanding heme requirements and regulation in apicomplexan parasites promises to reveal multiple targets for much-needed therapeutic intervention against these parasites. Antioxid. Redox Signal. 17, 634-656.
\end{abstract}

\section{Introduction: Tetrapyrroles in Life, Legends, and Parasites}

$T^{n}$ ETRAPYRROLES ARE CRITICAL FOR ENERGY production and consumption in most of Earth's biosphere. They are responsible for the red color of our blood, the greens in our salad, and maybe even the werewolves and vampires of folklore. Their ubiquity among all three domains of life (Bacteria, Archaea, and Eukarya) suggests that tetrapyrroles assumed a central function early in the evolution of life. Nevertheless, there are some critical variations in how different organisms synthesize their tetrapyrroles $(9,143)$. The acquisition by eukaryotes of the tetrapyrroles heme and chlorophyll was major drivers in two of the most important events in cellular evolution-the endosymbiotic origin of mitochondria and plastids (chloroplasts) from bacterial antecedents. In this review, we will examine heme, a tetrapyrrole responsible for numerous cellular functions, including oxygen sensing and electron transport. We will focus, in particular, on the acquisition, functions, and breakdown of heme in a group of single-celled, obligate intracellular parasites called the Apicomplexa. As we shall see, heme is required for the survival of these organisms, and interfering with heme acquisition, functions, and breakdown provides promising therapeutic targets against some of the world's major parasitic diseases.

Tetrapyrroles comprise four pyrrole molecules that typically fuse into a cyclic, planar structure (Fig. 1). Tetrapyrroles frequently contain a metal ion at their core that is central to their role in biological redox reactions. Perhaps the bestknown, and biologically important, tetrapyrroles are chlorophyll and heme. Chlorophyll consists of a tetrapyrrole ring with a magnesium ion at its center (Fig. 1B); it is the major light-harvesting pigment of photosynthetic organisms, such as cyanobacteria, plants, and algae. Chlorophylls first evolved in Bacteria, where they are found in cyanobacteria, purple bacteria, and several other groups (51). Chlorophylls were transferred to eukaryotes with the acquisition of plastid organelles from cyanobacteria through the process of endosymbiosis. This enabled eukaryotes to become photoautotrophs, a major event in eukaryotic evolution that led to the evolution of plants and numerous lineages of algae. In cyanobacteria and plastids, chlorophyll is a major component of photosystem complexes. Chlorophyll absorbs light of blue

${ }^{1}$ Research School of Biology, Australian National University, Canberra, Australia.

${ }^{2}$ Plant Cell Biology Research Centre, School of Botany, University of Melbourne, Parkville, Australia. 


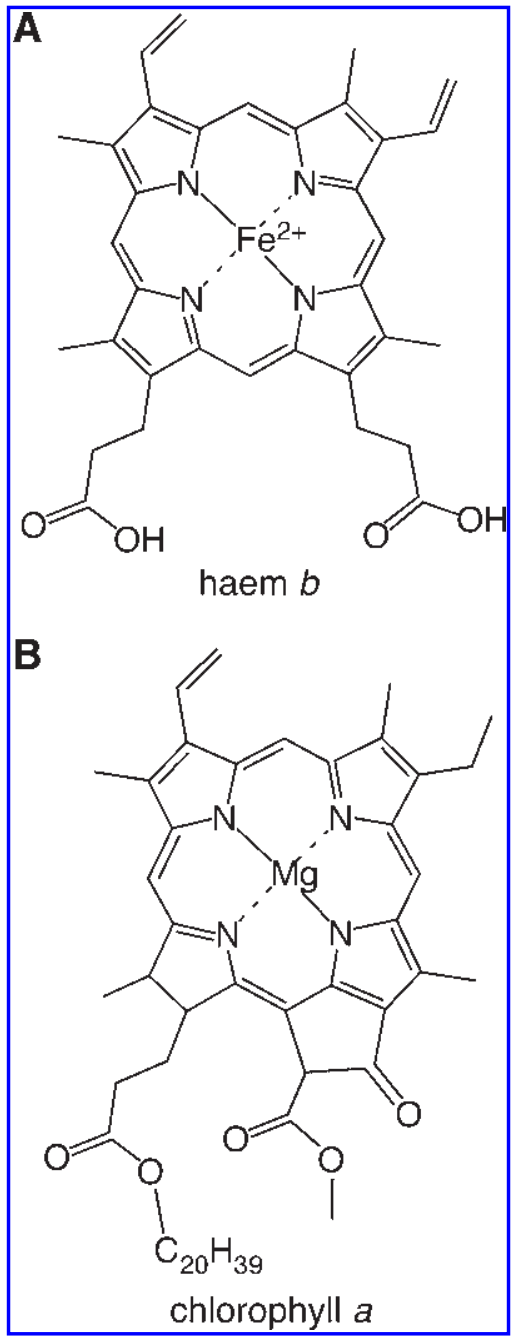

FIG. 1. The structure of tetrapyrroles. Tetrapyrroles consist of four pyrrole molecules arranged in a planar ring. (A) The structure of heme $b$, also known as protoheme, the simplest form of heme. Note the iron at the center of the ring that participates in redox reactions. (B) The structure of chlorophyll $a$. Note the magnesium ion at the center of the ring.

and red wavelengths (which gives the pigment its characteristic green color) and transfers this energy through to a central pair of chlorophyll molecules at the reaction center of the photosystem. The flow of energy into this reaction center results in the excitation of the chlorophyll pair and the release of an electron. The subsequent journey of this electron through an electron transport chain (ETC) results in the generation of adenosine triphosphate (ATP) and nicotinamine adenine dinucleotide phosphate (NADPH), which serve as energy currency to generate sugars in the so-called "dark" reactions of photosynthesis. Most of Earth's organic material is initially derived from photosynthesis. Photosynthesis also results in the generation of oxygen, which is formed through the oxidation of water to replenish the electrons lost at the reaction center chlorophylls. Indeed, virtually all of the oxygen found in Earth's atmosphere is a by-product of photosynthesis.

Heme is also adept at transferring electrons, but in this case they are derived from the iron at the center of the tetrapyrrole molecule (Fig. 1A). In certain proteinaceous environments, the iron in heme can also bind gases such as oxygen. Perhaps the best-known biological role of heme is in the vertebrate protein hemoglobin. Hemoglobin occurs in erythrocytes (red blood cells) and contains heme prosthetic groups that bind oxygen and transport it around the body. Heme belongs to a subset of tetrapyrrole molecules known as porphyrins. Porphyrins are distinguished by their purple color (porphyrin is derived from the Greek word for purple), and it is the heme in hemoglobin that gives blood its characteristic red color.

Given the structural similarities between chlorophyll and heme (Fig. 1), it is perhaps not surprising that these and other tetrapyrroles (such as vitamin $\mathrm{B}_{12}$, a cobalt-containing prosthetic group found in numerous enzymes) are synthesized by a broadly similar metabolic pathway. Tetrapyrrole biosynthesis is critical for the survival of most organisms that utilize tetrapyrroles. In plants, compounds that inhibit tetrapyrrole synthesis (e.g., acifluorfen) are potent herbicides. In humans, partial defects in heme synthesis lead to a set of medical conditions known as the porphyrias (7). Porphyrias result in the accumulation of various heme synthesis intermediates. Several of these intermediates produce free radicals upon exposure to light that result in (sometimes extreme) sensitivity to sunlight, skin blistering, and increased hair formation. Indeed, some hold that folkloric stories of werewolves and vampires stem from sufferers of porphyrias [e.g., (55)]. The phototoxicity of porphyrins can also be utilized for medical benefit in a process known as photodynamic therapy (166). Patients can be treated with modified porphyrins, or with early intermediates of heme biosynthesis that result in accumulation of protoporphyrin IX, the immediate precursor of heme. The targeted exposure of a light source to desired tissue (e.g., cancerous tumors) results in the production of free radicals that cause localized tissue death in a minimally invasive way.

Heme is essential to almost all living organisms and its synthesis is a core metabolic pathway. Parasites, by their very nature, are adept at acquiring nutrients, potentially including heme, from their host organisms. Nevertheless, heme is a toxic molecule, causing peroxidation of membrane lipids, and damage to DNA and proteins, all of which can lead to cell death (74). Host organisms must, therefore, limit their pool of free heme. This means that heme may not be readily available to parasites, suggesting that some may synthesize their own heme. Indeed, numerous apicomplexan parasites such as the causative agents of malaria and toxoplasmosis contain all the genes necessary for heme synthesis $(41,129,160)$. We will examine the acquisition of heme in this group of intracellular parasites later in this review. We will first, however, examine the uses and synthesis of heme in nonparasitic organisms.

\section{What Are the Functions of Heme?}

Heme serves as a prosthetic group on a broad range of proteins, and is also a central component of ETCs. Perhaps the best-known role for heme is as a prosthetic group on globin proteins. Globins are broadly distributed in all three domains of life $(39,80)$. Globin proteins contain a distinctive "globin" fold consisting of numerous alpha helices, and a heme moiety that is co-ordinated through interaction with an invariant histidine residue. In this arrangement, the iron molecule in heme is able to reversibly bind to oxygen, nitric oxide, and other gases. Globins probably first evolved as oxygen-sensing 
proteins in prokaryotes, enabling them to respond to local levels of oxygen $(38,167)$. Other globin functions are seen in vertebrate hemoglobins, which bind oxygen and transport it around the animal in the bloodstream. Leghemoglobins of legume plants sequester oxygen in root nodules, to prevent it from inhibiting the nitrogenase enzyme of symbiotic bacteria that fixes atmospheric nitrogen for the plant.

Heme also acts as a prosthetic group on catalases and some classes of peroxidases, both of which serve as critical antioxidant defenses in many organisms $(179,180)$. Hydrogen peroxide is a common reactive oxygen species generated by aerobic organisms as a by-product of processes such as electron transport in respiration and photosynthesis. Typically, these electron transport processes generate superoxide anions that are either spontaneously or catalytically converted to hydrogen peroxide. Hydrogen peroxide damages nucleic acids and proteins, and this oxidative stress can lead to cellular death. It is therefore critical that organisms have mechanisms to limit the abundance of hydrogen peroxide. Peroxidase and catalase enzymes catalyze the cleavage of hydrogen peroxide to form biologically inert molecules. In both catalases and heme-containing peroxidases, electrons from the central iron of heme reduce hydrogen peroxide to form water (48). Catalases also have the unique ability to oxidize hydrogen peroxide to form oxygen gas, with electrons donated to the heme iron. There are several classes of heme-containing peroxidases $(48,122,180)$. These include cytochrome $c$ peroxidases, which use cytochrome $c$ - a component of ETCs-as a donor of electrons to reduce hydrogen peroxide. Ascorbate peroxidases use ascorbate as the electron donor in hydrogen peroxide reduction. Catalase-peroxidases, like catalases, catalyze both the oxidation and reduction of hydrogen peroxide to form water and oxygen gas, although there is no sequence similarity between the two.

In addition to their role in oxygen sensing, oxygen carrying, and antioxidant defenses, heme-containing proteins have several other key roles in eukaryotic cells. Cytochrome $b_{5}$ proteins are a family of heme $b$-containing proteins that function in donating electrons to a variety of biochemical reactions, for example, in desaturation of steroids and fatty acids (131). Similar roles are ascribed to the diverse cytochrome P450 family of enzymes, which are distributed in a broad range of prokaryotic and eukaryotic organisms (158).

As already alluded to, heme is a critical component at several stages of the ETCs central to respiration and photosynthesis. Since this review covers nonphotosynthetic organisms, we will not elaborate on the role of heme in photosynthesis, but it is worth noting that this process has many similarities to the ETC involved in respiration (51). Instead, we will focus on the ETC that occurs during respiration, a process that occurs at the inner membrane of the mitochondria of many eukaryotes, as well as on the inner or cytoplasmic membrane of many prokaryotes. Mitochondria were originally derived through the endosymbiotic acquisition of an $\alpha$-proteobacterium, an event that occurred at the dawn of eukaryotic evolution. Eukaryotes therefore derived their mitochondrial ETC, and possibly also heme, from this symbiotic event.

The mitochondrial inner membrane contains numerous dehydrogenases that constitute the entry points of electrons into the ETC. Classically, these dehydrogenases include nicotinamine adenine dinucleotide (NADH) dehydrogenase (the so-called complex I of the ETC) and succinate dehydrogenase (complex II), in addition to various other dehydrogenases that we will cover later in this review. All of these dehydrogenases pass electrons to oxidized coenzyme Q (also called ubiquinone) to form reduced coenzyme $Q$ (called ubiquinol). For example, succinate dehydrogenase is a multiprotein complex that catalyzes the oxidation of succinate to form fumarate. The electrons derived from succinate are transferred through several co-factors, including flavin adenine dinucleotide (FAD) and iron-sulfur clusters, to coenzyme Q [(127); Fig. 2]. Succinate dehydrogenase contains a heme prosthetic group, although the role of this heme in electron transport is unclear (127). The NADH dehydrogenase complex (also called NADH:ubiquinone reductase) accepts electrons from NADH and transfers them to coenzyme Q. During this process, NADH dehydrogenase translocates protons from the mitochondrial matrix to the intermembrane space. Along with two other proton-translocating components of the ETC (discussed later in this section), NADH dehydrogenase contributes to the generation of a proton gradient and membrane potential $(\Delta \Psi)$ across the inner mitochondrial membrane. This proton gradient has numerous uses in the mitochondrion: (i) it can be harnessed by an F-type ATP synthase to generate ATP, (ii) it is critical for importing proteins into the organelle, and (iii) it has a crucial role in solute transport across the inner membrane $(17,115,127)$.

Coenzyme $Q$ is a hydrophobic molecule embedded in the inner mitochondrial membrane. Coenzyme $Q$ shuttles electrons from the various inner membrane dehydrogenases to another complex in the inner membrane known as cytochrome $c$ reductase (also called cytochrome $b c_{1}$ complex or complex III; Fig. 2). Reduced coenzyme Q carries two electrons. These electrons are donated to two separate electron acceptors within cytochrome $c$ reductase (24). The first is donated to the iron-sulfur cluster of the so-called Rieske protein of the cytochrome $c$ reductase complex. This electron is further donated to the heme group of cytochrome $c_{1}$, another protein in the cytochrome $c$ reductase complex, which then passes it on to cytochrome $c$, a mobile protein peripherally associated with the complex. The second electron in coenzyme $Q$ transfers through two heme groups of the cytochrome $b$ protein of the complex, and is ultimately donated to oxidized coenzyme $\mathrm{Q}$ that docks at a second site within the complex (24). Two such transfers form fully reduced coenzyme $Q$, which can then again donate electrons at the first coenzyme $\mathrm{Q}$ docking site in the complex. The net reaction of cytochrome $c$ reductase, therefore, results in one of the two electrons from reduced coenzyme $\mathrm{Q}$ being transferred to cytochrome $c$. A consequence of electron transfer in cytochrome $c$ reductase is that protons are removed from the matrix side of the complex and added to the intermembrane space side of the complex (Fig. 2), resulting in a net movement of protons across the membrane that contributes to the proton gradient.

Cytochrome $c$ reductase is the first point in the ETC where heme is essential for electron transport. The cytochrome $b$ subunit of the complex contains two noncovalently bound heme molecules in the form of heme $b$, which represents the simplest form of heme (Fig. 1A). These heme $b$ moieties are coordinated between two histidine residues each, which bind to the iron at the center of heme from above and below the planar molecule. Cytochrome $c_{1}$ contains a single heme molecule that, unlike in cytochrome $b$, is covalently bound to the 


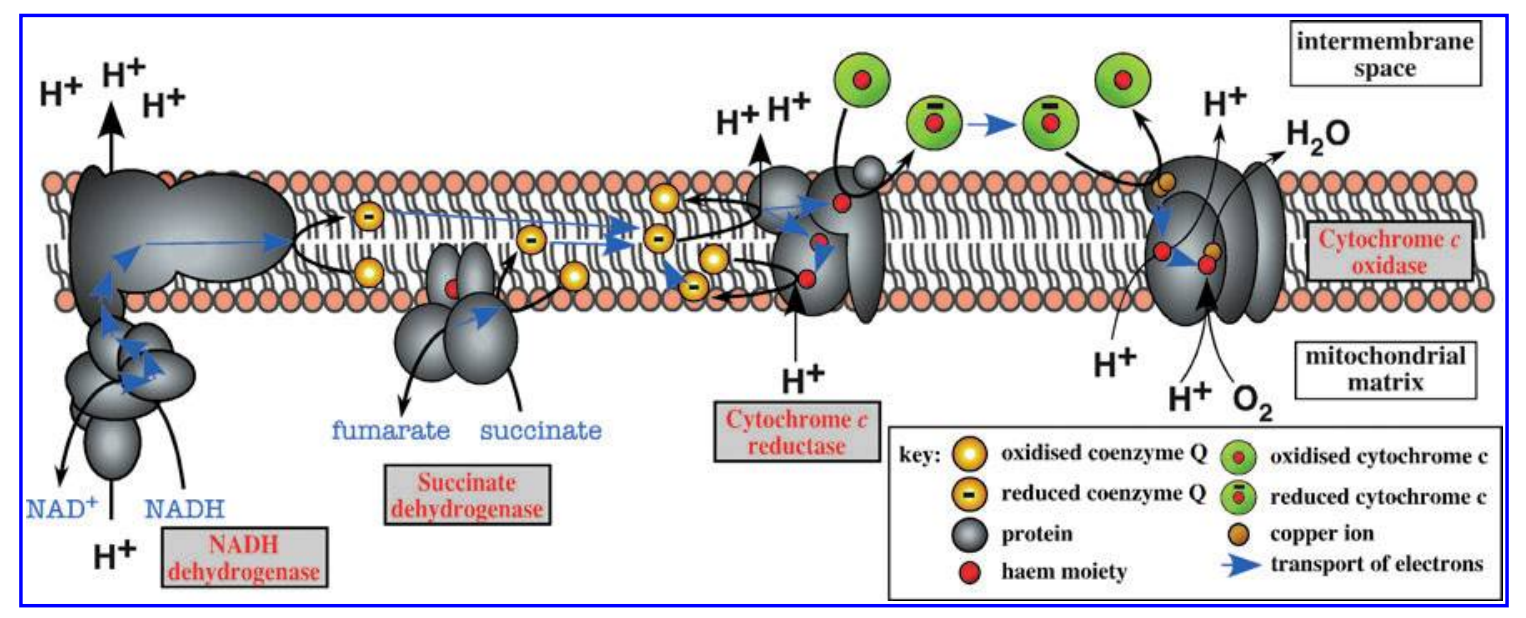

FIG. 2. The mitochondrial ETC that occurs in the inner mitochondrion membrane of most eukaryotes. The inner membrane contains several dehydrogenases, including NADH dehydrogenase (complex I) and succinate dehydrogenase (complex II), which feed electrons from various sources to coenzyme Q (yellow), a molecule embedded within the membrane. Reduced coenzyme $\mathrm{Q}$ donates electrons to cytochrome $c$ reductase (complex III). These electrons pass through several metal-based reaction centers, including heme (red), and ultimately reduce the heme prosthetic group of cytochrome $c$ (green). Cytochrome $c$ is a motile intermembrane space protein that donates electrons to cytochrome $c$ oxidase (complex IV). Cytochrome $c$ oxidase contains several metal centers, including two copper ions (orange) and two heme moieties, which ultimately donate electrons to oxygen, the terminal electron acceptor in the chain. The ETC generates a proton gradient and membrane potential across the inner membrane, which has several critical functions in the mitochondrion, including in the generation of ATP via an F-type ATP synthase. ATP, adenosine triphosphate; ETC, electron transport chain; NADH, nicotinamine adenine dinucleotide.

protein through two thioether bonds at conserved cysteine residues in a cysteine- $X-X$-cysteine-histidine amino acid motif (C-X-X-C-H motif) in the cytochrome protein (Fig. 5). In both cytochrome $b$ and cytochrome $c_{1}$, the transfer of electrons to heme involves the reduction of the iron molecule at the center of heme from the ferric $\left(\mathrm{Fe}^{3+}\right)$ state to the ferrous $\left(\mathrm{Fe}^{2+}\right)$ state.

Cytochrome $c$ localizes to the mitochondrial intermembrane space. In its oxidized form, cytochrome $c$ docks at the cytochrome $c$ reductase complex where it accepts electrons from cytochrome $c_{1}(54)$. Like cytochrome $c_{1}$, cytochrome $c$ has a single covalently bound heme prosthetic group at a conserved $\mathrm{C}-\mathrm{X}-\mathrm{X}-\mathrm{C}-\mathrm{H}$ motif. Reduced cytochrome $c$ migrates through the intermembrane space and docks with the cytochrome $c$ oxidase complex (also called complex IV; Fig. 2). Cytochrome $c$ donates electrons to a dinuclear copper site (called $\left.\mathrm{Cu}_{\mathrm{A}}\right)$ in cytochrome $c$ oxidase. These electrons are transferred to a heme moiety and then onto a second heme moiety that sits in a complex with a second copper ion (called $\left.\mathrm{Cu}_{\mathrm{B}}\right)(35,154,177)$. The final electron transfer of the mitochondrial ETC involves the reduction of oxygen at the heme/ $\mathrm{Cu}_{\mathrm{B}}$ center, resulting in the formation of water. Indeed, the vast majority of oxygen in aerobic eukaryotes is utilized as the terminal electron acceptor in the mitochondrial ETC. Like complexes I and III, electron transport through cytochrome $c$ oxidase drives the net transport of protons from the mitochondrial matrix to the intermembrane space (Fig. 2), contributing to the proton gradient across this membrane.

Both heme moieties in cytochrome $c$ oxidase exist as heme $a$ molecules. These differ from heme $b$ by the presence of formyl and hydroxyethylfarnesyl side groups on the tetrapyrrole molecule (Fig. 5). The farnesyl group is a product of isoprenoid synthesis, comprising a chain of three isoprenoid units. It increases the hydrophobicity of heme and is thought to stabilize the moiety within the cytochrome $c$ oxidase complex. The formyl group is thought to raise the redox poten- tial of heme, a critical requirement for accepting lower energy electrons that are transferred at the terminal end of the ETC (181).

\section{How Is Heme Made and Distributed Within Cells?}

Heme is a structurally complex organic molecule that requires multiple enzymatic reactions to synthesize. The mechanism of heme synthesis was unraveled by pioneering studies in the 1940s and 1950s. The first of these examined the fate of heavy isotopes of glycine after human ingestion, where the authors noted that glycine was incorporated in heme (135). Subsequent studies found that succinyl-CoA, an intermediate of the tricarboxylic acid cycle in the mitochondrion, was also incorporated into heme (42). The condensation of glycine and succinyl-CoA forms a molecule known as $\delta$ aminolevulinic acid (ALA), which represents the first committed precursor of tetrapyrrole biosynthesis. In $\alpha$ proteobacteria, animals, fungi, and some other eukaryotes, ALA synthesis is catalyzed by an enzyme known as ALA synthase [ALAS; Fig. 3; (64)]. In eukaryotes, ALAS localizes to the mitochondrion and contains a pyridoxal 5'-phosphate (vitamin $\mathrm{B}_{6}$ ) cofactor. ALAS is the major rate-limiting enzyme of heme synthesis in metazoa and many other organisms. Given the potential toxicity of heme, it is not surprising that ALA is tightly regulated at multiple levels, including transcription, messenger ribonucleic acid (mRNA) stability, protein stability, and even protein import into the mitochondrion (see section on Regulating Heme Metabolism).

After synthesis in the mitochondrion, ALA is exported from the organelle through unknown mechanisms (132). In the cytosol, two ALA molecules are condensed to form the pyrrole porphobilinogen, a reaction catalyzed by the enzyme porphobilinogen synthase (PBGS; also known as ALA dehydratase; Fig. 3). In animals, PBGS functions as an octamer and 


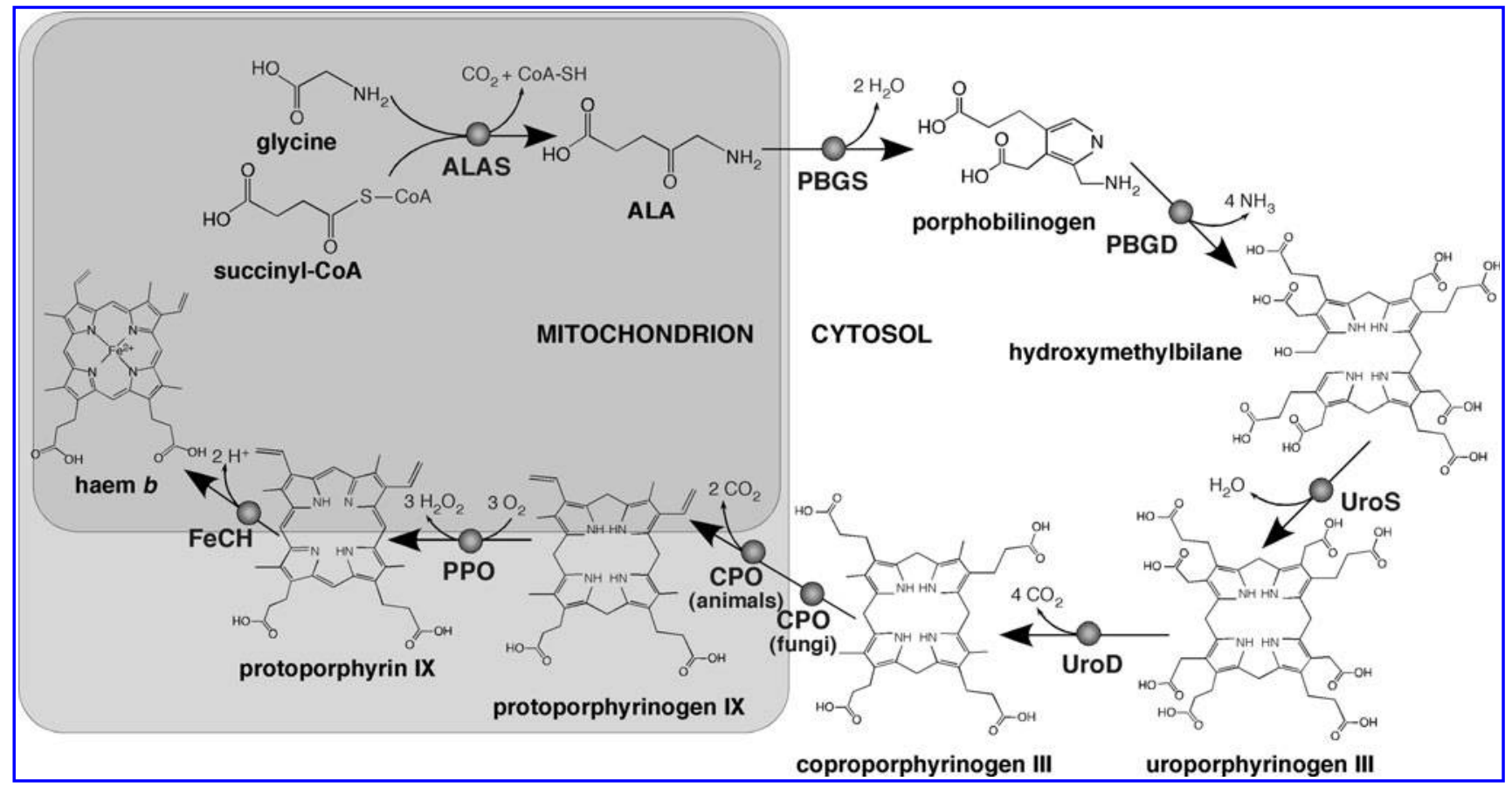

FIG. 3. Heme biosynthesis in animals and fungi. Heme synthesis is initiated in the mitochondrion, where ALAS reacts glycine and succinyl-CoA to form ALA. ALA is exported from the mitochondrion to the cytosol. Two molecules of ALA are condensed by PBGS to form the pyrrole porphobilinogen. Four porphobilinogen molecules are then condensed to form the tetrapyrrole hydroxymethylbilane, a reaction catalyzed by PBGD. Tetrapyrrole cyclization is catalyzed by UroS, forming uroporphyrinogen III. Uroporphyrinogen III is decarboxylated by UroD to form coproporphyrinogen III. Further decarboxylation generates protoporphyrinogen IX, a reaction catalyzed by CPO, which localizes to the cytosol in fungi and the mitochondrion in animals. Oxidation of protoporphyrinogen IX generates protoporphyrin IX, a reaction catalyzed by PPO at the intermembrane space side of the inner mitochondrion membrane. Finally, iron is inserted into the protoporphyrin ring to generate heme $b$, a reaction that is catalyzed by $\mathrm{FeCH}$ and which occurs on the matrix side of the inner membrane. ALA, $\delta$ aminolevulinic acid; ALAS, $\delta$-aminolevulinic acid synthase; $\mathrm{CPO}$, coproporphyrinogen III oxidase; FeCH, ferrochelatase; PBGD, porphobilinogen deaminase; PBGS, porphobilinogen synthase; PPO, protoporphyrinogen IX oxidase; UroD, uroporphyrinogen III decarboxylase; UroS, uroporphyrinogen III synthase.

contains zinc ions in the catalytic sites (22). PBGS is exquisitely sensitive to lead, which displaces zinc in the catalytic site; many of the symptoms of lead poisoning result from impaired PBGS activity. The next two steps of heme synthesis involve the formation of the tetrapyrrole ring. First, porphobilinogen deaminase (PBGD) catalyzes the condensation of four porphobilinogen molecules to form the linear tetrapyrrole hydroxymethylbilane (Fig. 3). PBGD also localizes to the cytosol and contains an unusual cofactor called dipyrromethane. Dipyrromethane structurally resembles two molecules of porphobilinogen and acts as a template for condensing more porphobilinogen molecules to form the tetrapyrrole (22). Next, the linear tetrapyrrole is cyclized to form uroporphyrinogen III, a reaction catalyzed by the cytosolic enzyme uroporphyrinogen III synthase [UroS; Fig. 3; (22)].

The remainder of heme synthesis involves various modifications to the tetrapyrrole ring. First, the cytosolic enzyme uroporphyrinogen III decarboxylase (UroD) catalyzes the decarboxylation of the four acetate side groups of uroporphyrinogen III to generate coproporphyrinogen III (CPIII) [Fig. 3; (22)]. Next, coproporphyrinogen III oxidase (CPO) decarboxylates two of the four propionate side groups of CPIII to form protoporphyrinogen IX. CPO localizes to the mitochondrion in animal cells, where it is associated with the intermembrane face of the inner mitochondrial membrane, but is localized to the cytosol in fungi [Fig. $3 ;(15,34,44)]$. The remaining enzymes of heme synthesis localize to the mitochondrion, the major site of heme requirement in most eukaryotes. The penultimate step of heme synthesis involves the oxidation of protoporphyrinogen IX to form protoporphyrin IX (Fig. 3). This reaction is catalyzed by inner mitochondrial membrane enzyme protoporphyrinogen IX oxidase (PPO), with oxygen acting as the electron acceptor $(22,27)$. The conversion of protoporphyrinogen IX to protoporphyrin IX is energetically favorable and can also occur in the absence of a catalyst. The synthesis of heme $b$ is completed when the enzyme ferrochelatase $(\mathrm{FeCH})$ inserts a ferrous iron into the center of the protoporphyrin IX ring, a reaction that occurs on the matrix side of the inner mitochondrial membrane [Fig. 3; (25)].

The greatest need for tetrapyrroles in photosynthetic eukaryotes such as plants and algae is in the plastid. Chlorophylls are a central component of light-harvesting complexes in photosynthesis, and heme is also required for electron transport in thylakoid membranes of plastids during photosynthesis. Plants also require heme in the mitochondrion and elsewhere in the cell. Early studies established some critical differences between tetrapyrrole synthesis in plants compared to nonphotosynthetic eukaryotes. These studies noted that plants are unable to synthesize ALA using glycine 


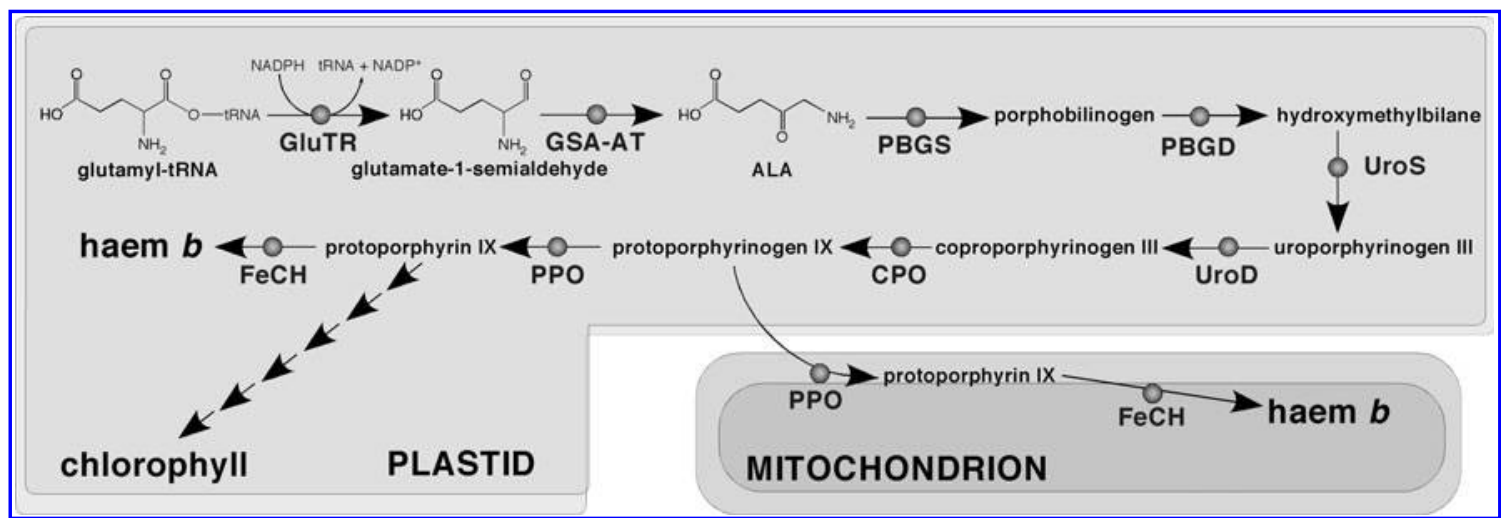

FIG. 4. Tetrapyrrole biosynthesis in plants commences with the synthesis of ALA by a two-step enzymatic process in the plastid. First, GluTR catalyzes the reduction of glutamyl-tRNA to form glutamate-1-semialdehyde. ALA is then formed from a transamination reaction catalyzed by GSA-AT. The remainder of the heme synthesis pathway features equivalent enzymes to those found in animals and fungi (see Fig. 3). The entire heme pathway occurs within the plastid, although the last two enzymes (PPO and $\mathrm{FeCH}$ ) are also found in the mitochondrion, suggesting that plants have two sites of heme formation. The formation of protoporphyrin IX represents the branch point of the heme and chlorophyll synthesis pathways. GluTR, glutamyl-tRNA reductase; GSA-AT, glutamate semialdehyde aminotransferase.

and succinyl-CoA as precursors, but glutamate is readily incorporated (9). Further characterization of this pathway found that glutamyl-tRNA serves as the precursor for ALA synthesis. The enzyme glutamyl-tRNA reductase (GluTR) utilizes energy from NADPH to catalyze the formation of glutamate-1-semialdehyde (Fig. 4). Then, a second enzyme called glutamate semialdehyde aminotransferase (GSA-AT) converts glutamate-1-semialdehyde to ALA. Glutamatederived ALA synthesis is common to virtually all photosynthetic eukaryotes, and also occurs in Archaea and most

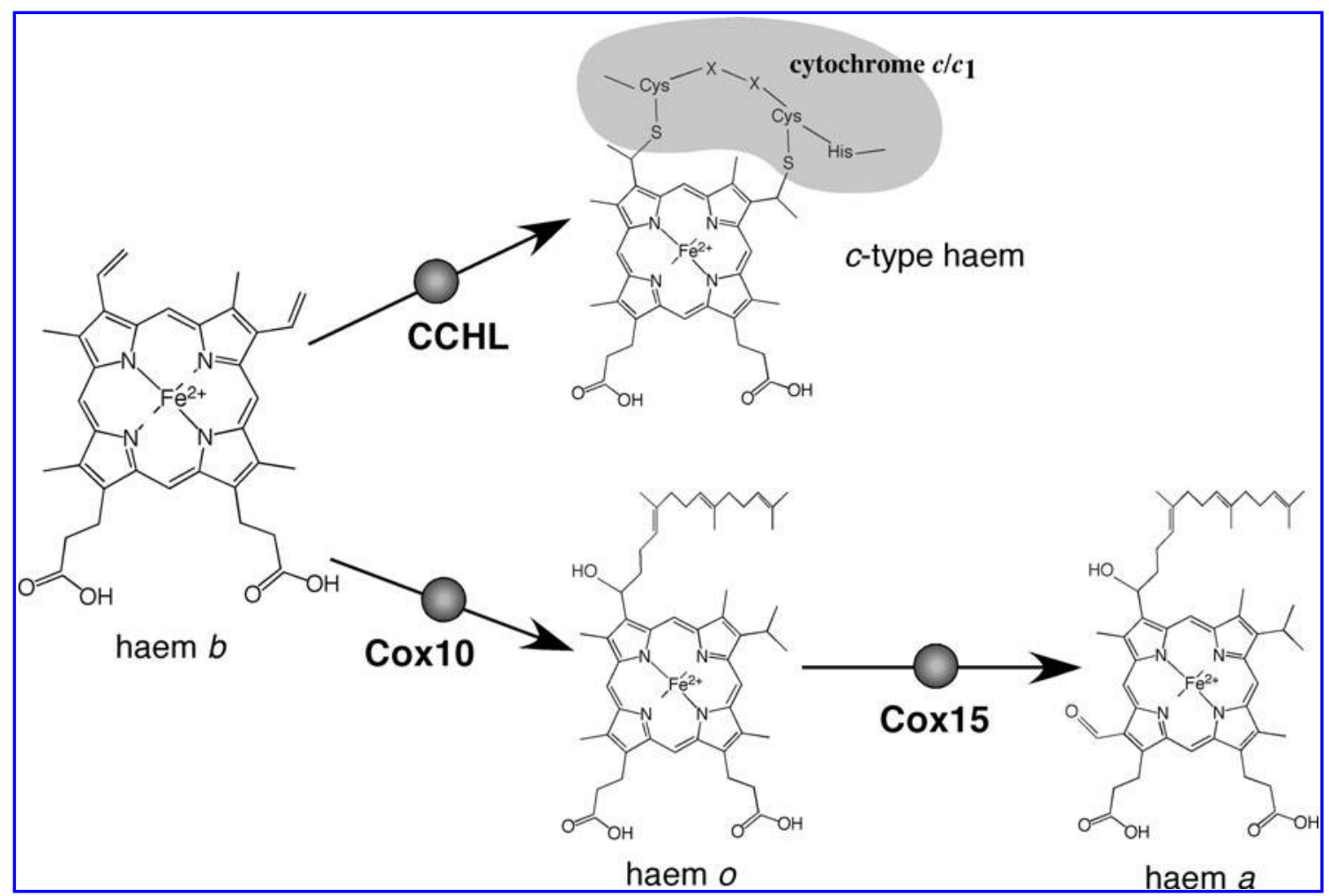

FIG. 5. Modifications of heme $\boldsymbol{b}$ in mitochondria. C-type cytochromes, such as cytochrome $c$ and cytochrome $c_{1}$, are formed through the covalent attachment of heme $b$ to two conserved cysteine residues in a C-X-X-C-H motif of the protein $(t o p)$. The iron molecule at the center of heme is co-ordinated by the histidine of the motif. In animals, fungi, and Apicomplexa, heme insertion into C-type cytochromes is mediated by an enzyme called CCHL. Heme $a$ is a critical component of the cytochrome $c$ oxidase complex of the mitochondrial electron transport chain (Fig. 2). Heme $a$ is formed through a two-step reaction from heme $b$ (bottom). First, a farnesyl group is attached to heme $b$ to form heme $o$, a reaction catalyzed by the enzyme Cox10. Cox15 then adds a formyl group to heme $o$ to form heme $a$. CCHL, cytochrome $c / c_{1}$ heme lyase; C-X-X-C-H motif, cysteine-X-X-cysteine-histidine amino acid motif. 
Bacteria. Indeed, glutamate-derived ALA synthesis has a considerably broader distribution than the ALAS-catalyzed reaction, which occurs only in $\alpha$-proteobacteria and nonphotosynthetic eukaryotes.

Another key difference between plants and nonphotosynthetic eukaryotes is that ALA synthesis occurs in the plastid rather than in the mitochondrion. The remaining enzymes of heme synthesis in plants and algae are homologous to the enzymes found in other eukaryotes, but they too localize primarily to the plastid (Fig. 4). This likely reflects the major requirement for heme and chlorophyll in the plastid. Some smaller differences also exist between photosynthetic and nonphotosynthetic eukaryotes. For example, the metal co-factor in the PBGS protein is magnesium instead of zinc (22). Interestingly, plants have two isoforms of PPO and $\mathrm{FeCH}$, the final two enzymes of the heme synthesis pathway. The two PPO genes have limited sequence identity, suggesting that they diverged very early in plant evolution (81). Interestingly, one PPO isoform localizes to the plastid, whereas the other localizes to the mitochondrion, or in some plants is dually targeted to the plastid and mitochondrion (Fig. 4). Similarly, one of the $\mathrm{FeCH}$ isoforms localizes to the plastid, while the other appears dually targeted to the plastid and the mitochondrion (22). This suggests that the final steps of heme synthesis can take place in both the plastids and mitochondria of plants (Fig. 4). This requires that protoporphyrinogen IX is exported from plastids and is imported into mitochondria, but mechanisms for this are unknown (56). The contribution of the two heme genesis pathways (mitochondrial and plastid) to heme required elsewhere in the cell is also unknown, although the amount of heme synthesized in plastids is considerably more than in mitochondria (21).

The synthesis of protoporphyrin IX is the last common step of heme and chlorophyll biosynthesis (Fig. 4). In chlorophyll biosynthesis, a Mg-chelatase inserts a magnesium ion into protoporphyrin, which is then modified in various ways to generate chlorophyll. The importance of tetrapyrroles for plant growth and viability is highlighted by the use of diphenyl ether herbicides (such as acifluorfen) that target the PPO enzyme.

Plastids were acquired by eukaryotes through a process of endosymbiosis from a cyanobacterial progenitor. Plastid acquisition postdates the acquisition of mitochondria, indicating that the glutamate-derived heme synthesis pathway was acquired with the cyanobacterial symbiont. It is therefore likely that the mitochondrial/cytosol and the plastid pathways for tetrapyrrole synthesis co-existed at some point in plant evolution. Plants apparently then streamlined their metabolism by discarding the mitochondrial/cytosol pathway and came to rely solely on the plastid-localized pathway. Interestingly, both the mitochondrial/cytosol and the plastid pathways co-exist in the protist Euglena $(69,171)$. Euglena is a photosynthetic eukaryote that acquired its plastid through a so-called secondary endosymbiotic event where a green alga became incorporated into a heterotrophic eukaryote. Instead of losing the mitochondrial/cytosol-localized pathway like in plants, the two pathways persist in Euglena $(69,171)$. The plastid-derived pathway probably provides all the heme and chlorophyll needed in the plastid, while the mitochondrial/ cytosolic pathway presumably generates the heme needed in the mitochondrion and possibly the rest of the cell (69). Curiously, Euglena plastids are surrounded by three membranes rather than the two observed in plants. One possible reason for the retention of two independent heme pathways in Euglena is that the additional membrane never evolved the necessary transporter to export heme from the plastid to the rest of the cell, meaning that the plastid pathway would be unable to supply cellular heme. Interestingly, Euglena cells can lose their plastids entirely and live a heterotrophic lifestyle (108). The fact that Euglena can still synthesize heme in the absence of a plastid is likely crucial in permitting plastid loss, which never occurs in plants, even if they are nonphotosynthetic (69).

Heme $b$ has several possible fates within cells. In the mitochondrion, it can be inserted into $b$-type cytochromes such as cytochrome $b$ in complex III of the ETC. It can also be covalently bound to a C-X-X-C-H motif of c-type cytochromes, such as cytochrome $c$ and $c_{1}$. The two cysteines of the motif bind to heme through thioether bonds, and the histidine residue co-ordinates the iron at the center of the ring (Fig. 5). Covalent insertion of heme into $c$-type cytochromes in fungal and animal mitochondria is mediated by a single-subunit, intermembrane space-localized enzyme known as cytochrome $c / c_{1}$ heme lyase [Fig. $5 ;(3,71)$ ]. In plant mitochondria, heme is also inserted into a C-X-X-C-H motif of cytochrome $c$, but this insertion requires a multiprotein pathway similar to that found in many prokaryotes. Heme $b$ can also be modified to heme $a$, which inserts into the cytochrome oxidase complex of the respiratory chain. Heme $a$ is formed through a two-step process. First, a farnesyl group (a product of isoprenoid synthesis) is added to heme $b$ to form heme $o$, a reaction catalyzed by a farnesyl transferase protein called Cox10 (Fig. 5). Finally, a formyl group is generated on heme $o$ by the Cox15 protein to form heme $a$ (95).

Heme is required outside the mitochondrion, where it functions as a prosthetic group in proteins, such as globins, peroxidases, catalases, and cytochrome P450s. Despite its hydrophobic nature, heme cannot freely diffuse across cellular membranes, including the two membranes enclosing the mitochondrion (72). How heme is exported from mitochondria is unknown. Several studies have identified a possible role for ATP-binding cassette $(\mathrm{ABC})$ transporters in the transport of heme and other porphyrins into and out of the mitochondrion (20, 73). ABC transporters are multimembrane-spanning proteins that utilize energy from the hydrolysis of ATP to transport solutes across membranes. Mammalian cells contain several mitochondrially localized ABC transporters. One such transporter, called ABCB6, occurs on the outer membrane. ABCB6 appears to have a key role in transporting CPIII-the final heme biosynthesis intermediate synthesized in the cytosol-into the mitochondrion, where the heme synthesis pathway concludes [Fig. 3; (73)]. The ABCB10 transporter localizes to the inner membrane where it interacts with $\mathrm{FeCH}$, the terminal enzyme of heme synthesis (20). It is possible that ABCB10 is able to transport heme synthesized by $\mathrm{FeCH}$ out of the organelle. Although direct evidence for this is lacking, it is intriguing to note that an ABCB10 homologue is absent from the nematode worm Caenorhabditis elegans, which lacks the heme synthesis pathway, and does not need to export heme from the organelle (72).

Once in the cytosol, heme must be transported to various sites within the cell. The cytotoxic effects of heme mean that cells must keep intracellular free heme pools to a minimum. One way to do this is by binding free heme to heme-binding 
proteins that mediate transport around the cell (132). Although cells contain numerous cytosolic proteins with a high affinity for heme, cytosolic heme carrier proteins (HCPs) have not yet been identified. In addition to heme synthesis, mammals are able to acquire dietary heme absorbed in the intestine. Intestinal epithelial cells contain several proteins that may mediate heme uptake, although the mechanism for heme uptake remains unclear. Candidates for heme uptake proteins include a low-affinity heme transporter called HCP1, whose major role is in folate transport $(117,134)$, and a so-called heme responsive gene (HRG) family that includes HRG-1 and HRG-4 $(104,119)$.

\section{Heme Metabolism in Apicomplexan Parasites}

Apicomplexa are a phylum of intracellular parasites that have major impacts on human populations throughout the world. The most notorious apicomplexan is the malariacausing parasite Plasmodium, in particular P. falciparum, which causes cerebral malaria. Plasmodium parasites are transmitted to humans by mosquito bites. The parasites pass through a liver stage, and then infect erythrocytes, which constitutes the disease-causing part of the lifecycle. Over a third of the world's population is at risk from malaria, with more than 1 million people (predominantly children in sub-Saharan Africa) succumbing annually (45). The distribution of malaria has a strong correlation with poverty, and the medical, social, and economic impacts of the disease are profound in regions where it is prevalent. Toxoplasma gondii is a widespread apicomplexan parasite that infects virtually all nucleated mammalian cells and can cause encephalitis in immunocompromised individuals and ocular damage in healthy individuals. Babesia species and Theileria species belong to the Piroplasmid order of Apicomplexa. Both are major parasites of cattle and other livestock and are spread through tick bites. Like Plasmodium, Babesia infects erythrocytes, whereas Theileria sets up home inside leukocytes, co-opting the cell division machinery to proliferate, before differentiating into an erythrocyte-infecting form prior to transmission back into the tick (168). The final apicomplexan parasite we will consider in this review is Cryptosporidium, a gastrointestinal parasite that causes diarrhea symptoms and is responsible for several widespread outbreaks of disease.

\section{The use of heme in Plasmodium parasites}

Extensive genome sequencing and annotation in eight different Plasmodium species (collated and annotated at www.plasmodb.org) reveals the presence of multiple hemecontaining proteins and protein complexes. Foremost among these are proteins involved in the mitochondrial ETC. The $P$. falciparum genome encodes proteins that, based on homology with components in other organisms, constitute the cytochrome $c$ reductase (complex III) and cytochrome $c$ oxidase (complex IV) of the ETC (Fig. 6). These include the hemecontaining proteins cytochrome $b$ and cytochrome $c_{1}$ (Table 1 ). The $P$. falciparum genome also contains two homologues of cytochrome $c$, the mobile carrier of electrons between complexes III and IV (Fig. 6; Table 1). Why two cytochrome $c$ homologues exist is unclear. The $P$. falciparum genome encodes two single-subunit cytochrome $c / c_{1}$ heme lyase genes, suggesting that insertion of heme into $C$-type cytochromes occurs through similar mechanisms as in fungi and animals
$(4,160) . P$. falciparum encodes CoxI, the protein of cytochrome $c$ reductase that co-ordinates the two heme $a$ moieties of the complex (Table 1). The P. falciparum genome also encodes homologues of the Cox10 and Cox15 proteins required for heme $a$ synthesis (Figs. 5 and 6).

The mitochondrial ETC is active in blood stages of Plasmodium parasites, and contributes to generating a $\Delta \Psi$ across the inner mitochondrial membrane $(40,141,156,157)$. Cytochrome $b$ is the target for atovaquone, a major antimalarial drug. Atovaquone is thought to act as a competitive inhibitor of coenzyme $\mathrm{Q}$ binding to cytochrome $b$, and treating parasites with atovaquone results in a rapid loss of $\Delta \Psi$ across the inner membrane and subsequent inhibition of parasite growth $(63,140)$. Mutations in cytochrome $b$ (a gene encoded on the mitochondrial genome of Plasmodium) can lead to atovaquone resistance, and such resistance has arisen in both laboratory and field settings, limiting the use of atovaquone in treating malaria.

The mitochondrial ETC is clearly critical for the survival of blood-stage Plasmodium parasites, but what is its role in cellular metabolism? At least five dehydrogenases can contribute electrons to the ETC via coenzyme Q [Fig. 6; (160)]. These include succinate dehydrogenase (complex II); malate:quinone oxidoreductase, which donates electrons acquired from the oxidation of malate; dihydroorotate dehydrogenase (DHOD), a pyrimidine biosynthesis enzyme that oxidizes dihydroorotate to form orotate; and a FAD-linked glycerol-3phosphate dehydrogenase, which oxidizes glycerol-3phosphate to form dihydroxyacetone phosphate. Plasmodium lacks a multisubunit complex I-type NADH dehydrogenase but does encode a single-subunit NADH dehydrogenase, which is able to oxidize NADH [Fig. 6; (10)]. The Plasmodium genome also contains most subunits of the ATP synthase complex that harvests the proton gradient formed by the ETC to generate ATP (8).

Interestingly, of all these functions, it appears that the only essential role of the ETC in Plasmodium blood-stage growth is as an electron sink for the DHOD reaction in pyrimidine synthesis (111). To demonstrate this, Painter et al. expressed the yeast DHOD enzyme in $P$. falciparum parasites. Yeast DHOD is unique in that it is a cytosolic enzyme that does not donate electrons to coenyzme Q. Expressing this cytosolic DHOD in Plasmodium will thus overcome the requirement for an active ETC in pyrimidine biosynthesis. When these parasites were treated with atovaquone to inhibit the ETC, the parasites survived, despite atovaquone collapsing the $\Delta \Psi$ across the inner membrane (111). These data suggested that the other dehydrogenases are dispensable for parasite growth in blood stages. In a separate approach to test for the role of the ETC in P. falciparum, Smilkstein et al. used drug selection to generate a $P$. falciparum strain resistant to cytochrome $c$ reductase inhibitors such as atovaquone (139). Unlike previously characterized atovaquone-resistant mutants, cytochrome $c$ reductase activity in these parasites remained sensitive to atovaquone. The authors concluded that, like in the yeast DHOD study, they had generated a parasite line that no longer required the mitochondrial ETC for parasite viability. This raises the question of what could function as the electron sink for the DHOD reaction in ETC-less parasites? One possibility is that instead of donating electrons to coenzyme Q, DHOD in these parasites may donate electrons to menaquinone, an electron carrier that can function in place of 


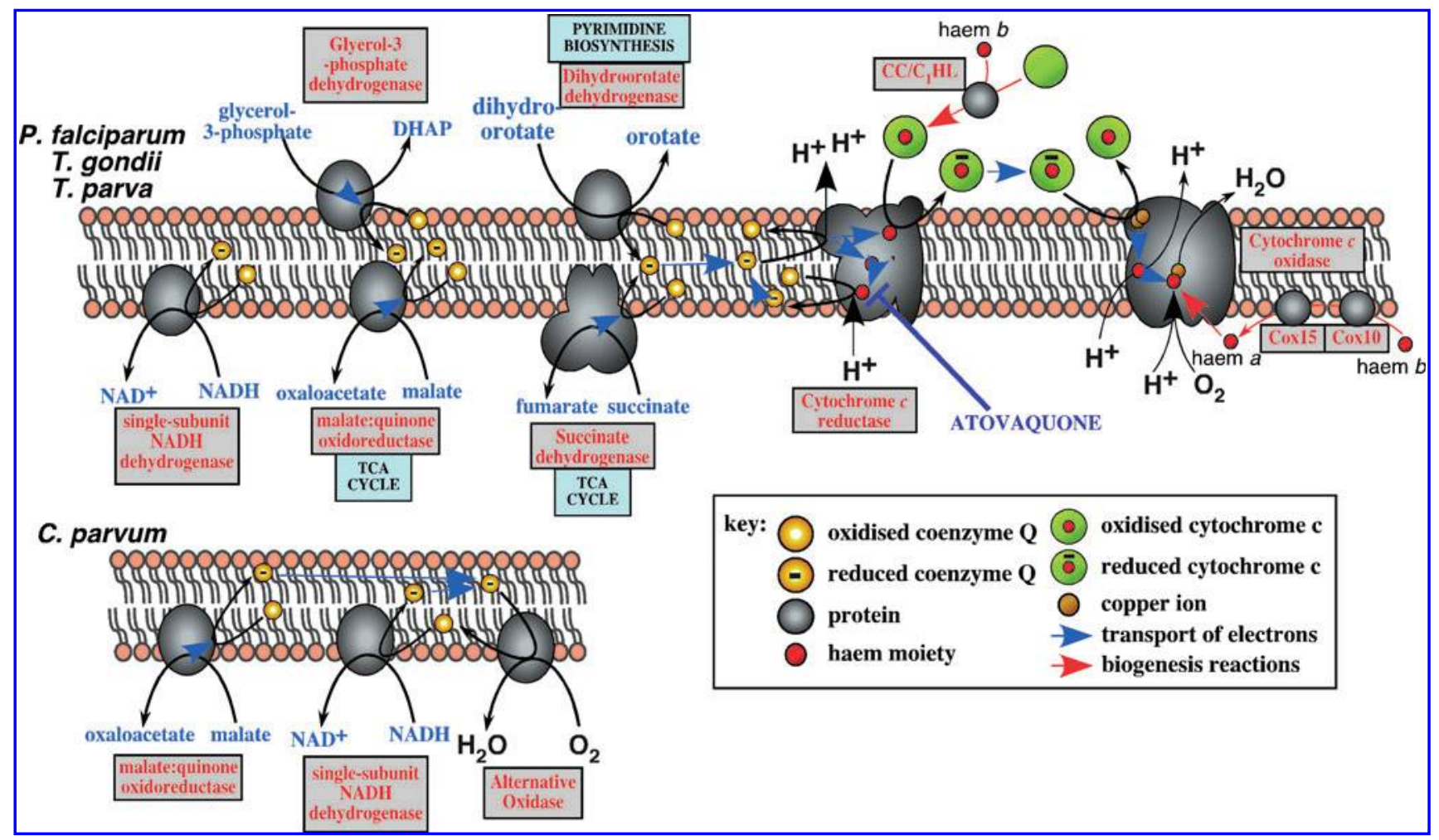

FIG. 6. The mitochondrial ETC in apicomplexan parasites. Five dehydrogenases feed electrons into the ETC of Plasmodium, Toxoplasma, and Theileria (top). These include the TCA cycle enzymes succinate dehydrogenase (complex II) and malate:quinone oxidoreductase, the pyrimidine synthesis enzyme dihydroorotate dehydrogenase, a single-subunit NADH dehydrogenase, and a glycerol-3-phosphate dehydrogenase. Note that apicomplexan succinate dehydrogenase appears to lack the conserved histidine residues that co-ordinate heme (93), suggesting that, unlike animal succinate dehydrogenase (Fig. 2), the apicomplexan complex does not bind heme. The remainder of the ETC resembles that found in "typical" eukaryotes. Cytochrome $c$ reductase (complex III) accepts electrons from coenzyme Q and ultimately reduces cytochrome $c$. Notably, cytochrome $c$ reductase is the target of the major antimalarial drug atovaquone. Electrons from cytochrome $c$ are donated to cytochrome $c$ reductase, where they ultimately reduce oxygen to form water. Proton transfer across the inner mitochondrial membrane occurs at both cytochrome $c$ reductase and cytochrome $c$ oxidase. The ETC in Cryptosporidium (bottom) differs considerably from that found in other Apicomplexa. Electrons are fed into the Cryptosporidium ETC by malate:quinone oxidoreductase and a single-subunit NADH dehydrogenase. Cryptosporidum lacks homologues of cytochrome $c$ reductase, cytochrome $c$, and cytochrome $c$ oxidase. Instead, reduced coenzyme $Q$ donates electrons to an alternative oxidase, which reduces oxygen in the terminal step of the ETC. TCA, tricarboxylic acid.

coenzyme $Q$ in several bacterial systems. It appears that menaquinone is present in blood-stage $P$. falciparum parasites, being upregulated in parasites grown in anaerobic conditions (P. falciparum usually grows as a microaerophile) (153). Menaquinone can act as an electron acceptor for the singlesubunit NADH dehydrogenase in $P$. falciparum, although direct evidence for its role as an electron acceptor for DHOD is lacking.

Blood-stage Plasmodium parasites rely on glucose as their major energy source, meaning that if ATP synthase has a role in ATP generation, it is only minor during blood stages. As mentioned previously, the Plasmodium lifecycle consists of mosquito and liver stages in addition to the blood stages so far discussed. Glucose levels in the insect hemolymph are roughly equivalent to that found in mammalian blood (85), suggesting that insect stages of Plasmodium can derive similar amounts of glycolytic energy to blood stages. Curiously, a knockout mutant of the single-subunit NADH dehydrogenase in the mouse malaria Plasmodium berghei was viable in blood-stage parasites, but essential during midgut (oocyst) development of the parasites in the mosquito (14). This suggests that there is an increased role for the ETC in insect stages of the parasite. One possible explanation is that insect stages require more energy than blood stages, necessitating a more active ETC capable of synthesizing higher levels of ATP. It will now be of considerable interest to generate mutants in ATP synthase subunits to directly address this possibility. In the broader context of heme metabolism in Plasmodium, we can conclude that the parasite requires heme during both blood and insect stages for electron transport in the mitochondrion.

Outside the mitochondrion, Plasmodium contains few known heme-requiring proteins. The $P$. falciparum genome encodes three cytochrome $b_{5}$ homologues of unknown function and localization (Table 1 ; cytochrome $b_{5}-1,-2$, and -3 ). One of these (cytochrome $b_{5}-1$ ) contains a hydrophobic C-terminus that may function as a tail-anchor targeting motif for the endoplasmic reticulum or the outer mitochondrial membrane. $P$. falciparum appears to lack homologues of cytochrome P450 genes, and we were unable to identify obvious 
Table 1. Heme-Containing Proteins in a Range of Apicomplexa

\begin{tabular}{|c|c|c|c|c|c|}
\hline Protein & Function & P. falciparum & T. gondii & T. parva & C. parvum \\
\hline Cytochrome $b$ & $\begin{array}{l}\text { Mitochondrial electron } \\
\text { transport chain } \\
\text { (cytochrome } c \text { reductase) }\end{array}$ & $\begin{array}{l}\text { Mitochondrial } \\
\text { genome }\end{array}$ & $\begin{array}{l}\text { Mitochondrial } \\
\text { genome }\end{array}$ & $\begin{array}{l}\text { Mitochondrial } \\
\text { genome }\end{array}$ & Absent \\
\hline Cytochrome $c_{1}$ & $\begin{array}{l}\text { Mitochondrial electron } \\
\text { transport chain } \\
\text { (cytochrome } c \text { reductase) }\end{array}$ & PF14_0597 & TGME49_046540 & TP04_0384 & Absent \\
\hline Cytochrome c & $\begin{array}{l}\text { Mitochondrial electron } \\
\text { transport chain }\end{array}$ & PF14_0038 & TGME49_019750 & TP02_0396 & Absent \\
\hline Cytochrome $c-2$ & Unknown & MAL13P1.55 & TGME49_029420 & TP04_0712 & Absent \\
\hline CoxI & $\begin{array}{l}\text { Mitochondrial electron } \\
\text { transport chain } \\
\text { (cytochrome } c \text { oxidase) }\end{array}$ & $\begin{array}{l}\text { Mitochondrial } \\
\text { genome }\end{array}$ & $\begin{array}{l}\text { Mitochondrial } \\
\text { genome }\end{array}$ & $\begin{array}{l}\text { Mitochondrial } \\
\text { genome }\end{array}$ & Absent \\
\hline Cytochrome $b_{5}-1$ & Unknown & PFL1555w & TGME49_076110 & Absent & Absent \\
\hline Cytochrome $b_{5}-2$ & Unknown & PFI0885w & TGME49_113580 & Absent & $\operatorname{cgd} 2 \_1040$ \\
\hline Cytochrome $b_{5}-3$ & Unknown & PF14_0266 & TGME49_054090 & Absent & Absent \\
\hline Cytochrome $b_{5}-4$ & $\begin{array}{l}\text { Hydroxylation of fatty } \\
\text { acids-contains fatty } \\
\text { acid hydroxylase } \\
\text { domain in addition to } \\
\text { cytochrome } b_{5} \text { domain }\end{array}$ & Absent & TGME49_040770 & Absent & Absent \\
\hline Cytochrome $b_{5}-5$ & $\begin{array}{l}\text { Sulfite oxidation-contains } \\
\text { molybdenum-binding } \\
\text { sulfite oxidase domain }\end{array}$ & Absent & TGME49_095720 & Absent & Absent \\
\hline Cytochrome $b_{5}-6$ & unknown & Absent & TGME49_073530 & Absent & Absent \\
\hline Cytochrome $b_{5}-7$ & unknown & Absent & TGME49_076990 & Absent & Absent \\
\hline Cytochrome P450 & unknown & Absent & TGME49_115770 & Absent & Absent \\
\hline Catalase & Antioxidant defense & Absent & TGME49_032250 & Absent & Absent \\
\hline
\end{tabular}

${ }^{a}$ Gene model for TGME49_113580 is very likely incorrect. Correct gene model is probably similar to Neospora caninum gene model NCLIV_056850 (www.toxodb.org).

globin homologues in the P. falciparum genome. Antioxidant defenses in P. falciparum have been well characterized (62). They are required in the parasite cytosol, mitochondrion, and apicoplast, a nonphotosynthetic plastid organelle. P. falciparum contains several major types of antioxidant defenses: a glutathione-based system, a thioredoxin-based system, and two superoxide dismutases, but none of these systems require any heme-dependent proteins, such as catalases, ascorbate peroxidases, or cytochrome $c$ peroxidases.

\section{The abuse of heme in Plasmodium parasites}

Blood-stage Plasmodium parasites live within hemoglobinrich erythrocytes. Parasites engulf hemoglobin and other proteins from their host cell during intracellular growth by a process of endocytosis (46). Endocytic vesicles fuse with a lysosome-like compartment called the digestive vacuole where a suite of proteases digest hemoglobin to its constituent amino acids. These proteases include aspartic proteases (the plasmepsins), cysteine proteases (the falcipains in P. falciparum), the metalloprotease falcilysin, a dipeptidyl aminopeptidase, and aminopeptidases (33, 37, 65, 118). Plasmepsins likely perform the initial cleavage of hemoglobin, and then act in concert with falcipains to further degrade hemoglobin into shorter peptides. These are then cleaved by falcilysin into peptides $\sim 4$ to 10 amino acids long (33). A dipeptidyl aminopeptidase cleaves these short oligopeptides into dipeptides and aminopeptidases, then cleaves the final peptide bond to form the constituent amino acids $(65,118)$. Amino acids released from hemoglobin degradation are then transported into the parasite cytosol where they make up the bulk of amino acids utilized by the parasite in protein synthesis and other cellular functions (83).

The degradation of hemoglobin also releases heme into the digestive vacuole. Given the sheer volume of hemoglobin digested by the parasite $(\sim 70 \%$ of the total amount of hemoglobin in the erythrocyte), the large amount of heme released into the vacuole is potentially extremely toxic to the parasite. The parasite overcomes this by polymerizing heme into an insoluble pigment called hemozoin (110). Indeed, the vast majority of heme in the parasite (over 95\%) is thought to be in the form of hemozoin (31).

How parasites polymerize heme is controversial. Hemozoin is known to associate with neutral lipid droplets found in the digestive vacuole (116). Neutral lipid droplets can catalyze the formation of hemozoin in vitro, suggesting that hemozoin formation can occur at the surface of neutral lipid droplets found in the digestive vacuole $(49,50,116)$. Proteins have also been proposed to play a role in hemozoin formation, possibly mediating the initial nucleation event that precedes polymerization. Histidine-rich proteins (HRPs) found in P. falciparum can catalyze hemozoin formation in vitro, although at a low efficiency $(57,145)$. HRPs readily bind to heme, but HRP homologues are unique to $P$. falciparum, which perhaps suggests that other Plasmodium species can synthesize hemozoin without HRPs. Further, the majority of the best characterized HRP protein (HRP2) is secreted from the parasite into the host cell cytosol, suggesting that its major function may not be in the digestive vacuole $(2,53)$. Another recently identified protein candidate for hemozoin formation is the heme 
detoxification protein (PfHDP), which binds heme and can catalyze hemozoin formation in vitro at over 1000 times the efficiency of HRP2 and lipids (57). PfHDP appears to be exported to the host cell cytosol before being internalized into the digestive vacuole during endocytosis of host cell proteins.

Regardless of how hemozoin is formed, it is clearly critical for parasite survival. The major antimalarial drug chloroquine interferes with heme polymerization, resulting in a reduction in hemozoin, swelling of the digestive vacuole membrane, and rapid parasite death $(76,86,138,170)$. Exactly how chloroquine interferes with hemozoin formation is still not fully understood. Chloroquine binds to heme and may prevent its incorporation into hemozoin (32). Chloroquine can also bind to hemozoin and may cap hemozoin crystals to prevent the addition of further heme molecules (146). The accumulation of free heme in chloroquine-treated parasites likely compromises membrane integrity $(74,107)$. Heme (and heme in a complex with chloroquine) can also inhibit some of the enzymes that degrade hemoglobin $(43,161)$. Effects on membrane integrity and hemoglobin digestion likely inhibit parasite growth in chloroquine-treated parasites. Curiously, a chloroquine-resistant strain of $P$. berghei generated in laboratory conditions appears to lack hemozoin (114). Exactly how these parasites overcome the toxic effects of free heme is unclear, although these chloroquine-resistant parasites revert to chloroquine sensitivity in the absence of drug pressure (47).

Heme may also play a critical role in the action of artemisinin and its derivatives, another major class of antimalarial drugs. The activity of artemisinin is based on the presence of an endoperoxide bridge in the molecule. It is believed that cleavage of this endoperoxide bridge leads to the formation of reactive intermediates that can ultimately inhibit parasite growth (105). The iron present in reduced heme is a prime candidate for mediating this cleavage event. Interestingly, artemisinins have been proposed to act in both the digestive vacuole and mitochondrion of Plasmodium $(26,169)$, the two major sites for heme in these parasites. Indeed, inhibiting the digestion of hemoglobin, and therefore inhibiting the release of free heme into the digestive vacuole, limits the efficacy of artemisinin (66). Exactly how artemisinin inhibits parasite growth is not fully understood. Reactive intermediates may alkylate proteins and other molecules, including heme itself, either inferring with their functions or generating cytotoxic compounds $(91,105)$. Alternatively, reactive artemisinin intermediates may lead to the formation of reactive oxygen species, for example, by lipid peroxidation, that inhibit proteins and other cellular processes, and affect the integrity of cellular membranes (13).

While polymerizing heme is critical for the survival of blood-stage Plasmodium, the generation of hemozoin has unanticipated effects on parasite interactions with the host. When Plasmodium parasites exit host red blood cells, they leave behind a so-called residual body that contains cellular material that is not packaged into the daughter cells. This includes hemozoin crystals. Egress of parasites from host erythrocytes corresponds to the release of pro-inflammatory cytokines, such as tumor necrosis factor- $\alpha$ (TNF- $\alpha)$, which in turn corresponds to the fever associated with malaria (92). During Plasmodium infection, considerable levels of hemozoin are released into the blood system of the host. Several lines of evidence point to a role of this hemozoin as a critical mediator of the innate host cell immune response to Plasmodium.
Hemozoin can stimulate the production of TNF- $\alpha$ and other pro-inflammatory cytokines, as well as anti-inflammatory cytokines under certain conditions, through mechanisms not yet fully understood (136). Phagocytic cells of the immune system, such as monocytes, phagocytose hemozoin. The presence of hemozoin-containing monocytes correlates with reduced erythropoiesis (the generation of new erythrocytes), suggesting that hemozoin may also have a role in promoting anemia that is frequently associated with malaria $(18,113)$.

Mammalian cells detoxify heme through the action of heme oxygenase ( $\mathrm{HO})$. $\mathrm{HO}$ cleaves heme at a single point in the tetrapyrrole ring, linearizing the ring to produce a molecule called biliverdin, and releasing iron in the process (87). Biliverdin can be further catabolized and excreted from the organism. $P$. falciparum contains a single HO-like protein $(P f H O)$ that functions as a $\mathrm{HO}$ when assayed in vitro $(106,128)$. The role of PfHO in parasite metabolism remains unclear, although its role in deactivating free heme is likely very minor compared to the generation of hemozoin. Although PfHO was predicted to localize to the apicoplast based on a putative $\mathrm{N}$ terminal targeting domain (106), heme seems unlikely to be required for apicoplast enzymes (Table 1). Experimental localization of $P f H O$ is therefore critical in determining its role. One possible function for $\mathrm{PfHO}$ is iron scavenging. Iron released during the $\mathrm{HO}$ reaction can be incorporated into enzymes and other iron-requiring processes. Intriguingly, the apicoplast contains an iron-sulfur cluster synthesis pathway, and iron-sulfur clusters are essential for enzymes of several apicoplast metabolic pathways as well as the redox protein ferredoxin (120). One possibility we can propose is that heme serves as a molecule to transport iron into the apicoplast, with $\mathrm{HO}$ then releasing iron for use in iron-sulfur cluster synthesis. This scenario currently lacks any supportive evidence, and would require the existence of transporters able to transport heme across the four membranes that surround the apicoplast.

\section{Heme metabolism in other apicomplexa}

In addition to Plasmodium, we examined putative hemebinding proteins in a range of other Apicomplexa, including T. gondii, Theileria parva, and Cryptosporidium parvum. Mitochondria in T. gondii have an active ETC and parasites are highly sensitive to atovaquone $(6,165)$. The $T$. gondii genome encodes homologues of all the proteins that putatively comprise the ETC in Plasmodium, including the presence of all heme-binding proteins (Fig. 6). In addition to the five mitochondrial dehydrogenases found in P. falciparum, T. gondii contains a second NADH dehydrogenase homologue; although mutant studies indicate that neither protein is essential for parasite viability in the asexual tachyzoite life stage (82). Less is known about the mitochondrial ETC of T. parva, but genome mining indicates the presence of the same complement of genes as in P. falciparum (Fig. 6). Interestingly, like in Plasmodium, both T. gondii and T. parva encode two cytochrome $c$ homologues, so two cytochrome $c$ proteins could be a common feature of the mitochondrial ETC in Apicomplexa.

C. paroum contains a highly reduced mitochondrion whose major function is likely the synthesis of iron-sulfur clusters $(75,123)$. The C. paroum genome encodes two mitochondrial dehydrogenases (namely, malate:quinone oxidoreductase and a single-subunit NADH dehydrogenase), as well as the genes necessary for coenzyme $Q$ synthesis. This suggests the 
presence of a mitochondrial ETC. However, the genome lacks genes encoding any of the subunits for cytochrome $c$ reductase (complex III) and cytochrome $c$ oxidase (complex IV) (Table 1). Instead, electrons from coenzyme $Q$ are donated to a so-called alternative oxidase, a single-subunit protein that functions in place of complex IV to reduce oxygen [Fig. 6; $(124,148)]$.

Compared with P. falciparum, T. gondii contains several additional heme-containing proteins. These include a catalase protein that functions in antioxidant defense $(29,137)$, and a single cytochrome P450 homologue of unknown function (Table 1). In addition to putative orthologues of the three cytochrome $b_{5}$ proteins found in P. falciparum, T. gondii contains an additional four proteins with cytochrome $b_{5}-$ containing domains (Table 1). These include one protein that likely functions in fatty acid hydroxylation. Another cytochrome $b_{5}$-containing protein has homology to sulfite oxidases from other organisms. Sulfite oxidase is a molybdenumcontaining enzyme that oxidizes sulfite, for example, sulfite derived from the degradation sulfur-containing amino acids, to generate sulfate. Electrons from sulfite are donated to molybdenum, and then on to the heme group of the cytochrome $b_{5}$ domain of the enzyme to reoxidize the molybdenum (61). In mammalian cells the electrons from the cytochrome $b_{5}$ domain are then donated to cytochrome $c$ in the mitochondrial ETC. In T. parva, we were unable to identify any further heme-containing proteins beyond those of the mitochondrial ETC. Interestingly, we did identify a homologue of one of the P. falciparum cytochrome $b_{5}$-containing proteins in C. paroum, the only heme-containing protein we could identify in this organism (Table 1).

With respect to heme detoxification, T. gondii and T. parva both have homologues of PfHO (accession numbers TGME49_059190 and TP01_0873, respectively; www. eupathdb.org), suggesting that $\mathrm{HO}$ may be active in these parasites. Surprisingly, T. gondii and T. parva also have homologues of PfHDP (TGME49_085280 and TP04_0891), even though there is no evidence for hemozoin formation in either parasite. Both proteins appear absent from Cryptosporidium.

\section{Heme Acquisition in Apicomplexan Parasites}

Apicomplexan parasites clearly require heme for mitochondrial electron transport and several other cellular reactions. In this section, we will examine the possible sources for heme in Apicomplexa. We will consider the ability of parasites to synthesize their own heme from simple metabolic precursors, and the possibility that Apicomplexa scavenge heme from their host cells.

\section{Heme synthesis in apicomplexan parasites}

Blood-stage Plasmodium parasites live in a very heme-rich environment, but most of the heme internalized by the parasite is sequestered as hemozoin. To determine whether Plasmodium is capable of synthesizing its own heme, Surolia and Padmanaban incubated parasites with radiolabeled ALA (147). They observed the incorporation of the radiolabel into heme, indicating that P. falciparum does indeed synthesize heme. To ascertain the route of ALA synthesis, they incubated parasites in either radiolabeled glycine or radiolabeled glutamate, and found that only glycine labeled effectively into heme. This indicates that the route of ALA synthesis occurs through ALAS, as is the case in other nonphotosynthetic eukaryotes. This biochemical finding was supported by the identification of an ALAS homologue in the P. falciparum genome (172).

The genomes of $P$. falciparum and other Plasmodium species encode an almost complete complement of enzymes for the heme synthesis pathway (41). The T. gondii genome also appears to encode all the enzymes necessary for heme biosynthesis (www.toxodb.org). As mentioned earlier, the presence of ALAS activity and the absence of GluTR and GSA-AT activity in P. falciparum suggest that the heme synthesis pathway may resemble that observed in nonphotosynthetic eukaryotes. Nevertheless, most Apicomplexa (including Plasmodium, T. gondii, Babesia, and Theileria, but excluding Cryptosporidium) retain a nonphotosynthetic, plastid-derived organelle called the apicoplast $(67,88,173)$. When the apicoplast was first acquired, it was photosynthetic and had a plastid-localized tetrapyrrole synthesis pathway (58). Therefore, it is possible that some of these plastid-derived heme synthesis enzymes were retained by the parasites.

To test these possibilities, several groups set out to localize each of the heme synthesis enzymes in P. falciparum and $T$. gondii. As expected, the ALAS protein in both $P$. falciparum and T. gondii localizes to the mitochondrion [Fig. 7; $(129,163$, 175); G.v.D. and G.I.M., unpublished]. Unexpectedly, PBGS, the next enzyme in the pathway, localizes to the apicoplast [Fig. 7; $(28,129)]$. Like plastid-localized PBGS, the apicomplexan protein has an affinity for magnesium ions instead of zinc; although unlike the plant enzyme it is not dependent on magnesium for activity. Phylogenetic analyses suggest that apicomplexan PBGS is derived from the endosymbiont that gave rise to the apicoplast $(70,130,133)$. The different subcellular localizations and phylogenetic ancestry of ALAS and PBGS suggest that heme synthesis in Apicomplexa combines elements of both the mitochondrial/cytosolic and the

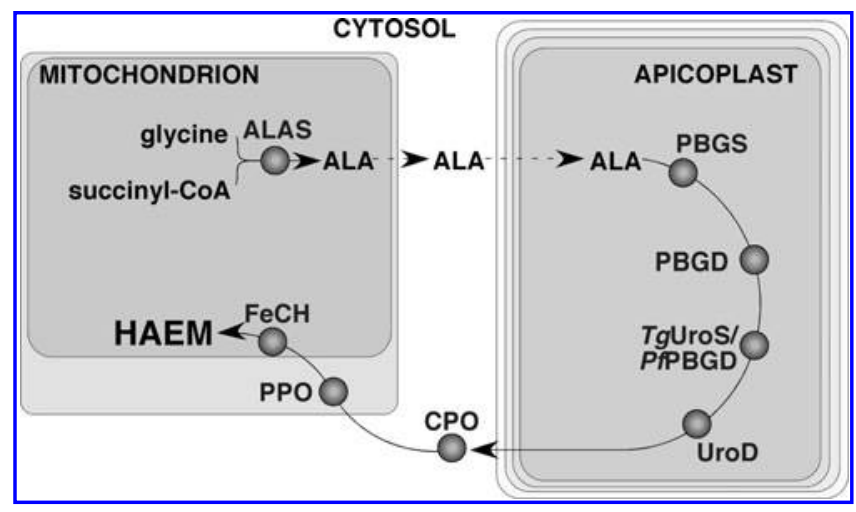

FIG. 7. Heme biosynthesis in Toxoplasma and Plasmodium. Heme biosynthesis commences with the ALAScatalyzed formation of ALA in the mitochondrion of Toxoplasma and Plasmodium. ALA is then transported from the mitochondrion into the stroma of the apicoplast. Here, the next four reactions of heme synthesis take place, leading to the formation of coproporphyrinogen III. Coproporphyrinogen III must then be exported from the apicoplast into the cytosol. Here, the enzyme CPO oxidizes coproporphyrinogen III to form protoporphyrinogen IX. Like in animal and fungal cells, the last two enzymes of heme synthesis localize to the mitochondria. 
plastidic pathways, which we previously termed a "hybrid" heme pathway (160).

The subsequent reactions up to the creation of CPIII-catalyzed by the enzymes PBGD, UroS, and UroD-also occur in the apicoplast in both P. falciparum and T. gondii [Fig. 7 ; $(97,98$, 129, 175); A.T.K. and G.v.D., unpublished]. Initially, we were unable to identify homologues of UroS in the $P$. falciparum genome (160). One study found that $P$. falciparum PBGD has both PBGD and UroS activity, suggesting it may take the place the UroS enzyme (98). More recently, a possible UroS homologue has been identified in the P. falciparum genome, although the localization and activity of this enzyme are unknown (70).

The next step of the pathway is catalyzed by CPO, which localizes to the cytosol in both P. falciparum and T. gondii [Fig. $7 ;(100,175)]$. This reflects the localization of CPO in fungi, and phylogenetic analyses indicate that $\mathrm{CPO}$ in Apicomplexa is more closely related to CPO from fungi and animals than from plants and other photosynthetic organisms $(15,70)$. The final two enzymes of heme biosynthesis in Apicomplexa (PPO and $\mathrm{FeCH}$ ) localize to the mitochondrion [Fig. 7; $(99,101,160,175)]$, indicating that the mitochondrion is the ultimate site of heme synthesis. A curious feature of PPO is that it does not utilize oxygen as an electron acceptor (compare Fig. 3), and instead may reduce coenzyme $Q$ in the mitochondrial ETC (99).

\section{The evolution of heme synthesis in apicomplexan parasites}

The localization of enzymes for heme synthesis in Apicomplexa presents an unusual hybrid of the pathways found in photosynthetic and nonphotosynthetic organisms. To understand how such a biochemical mosaic could evolve, Koreny et al. examined heme biosynthesis in Chromera velia (70). C. velia is a single-celled, photosynthetic alga and is probably the sister group of the Apicomplexa (94). The plastid of $C$. velia and the apicoplast of Apicomplexa were derived from the same endosymbiotic event, likely from a red algal symbiont incorporated into the common ancestor of Apicomplexa and a related group of algae called dinoflagellates (58). Koreny et al. identified homologues for seven of the eight enzymes required for heme synthesis in Chromera (they did not identify PPO). They identified an ALAS homologue (CvALAS) and performed radiolabeling experiments with glycine and glutamate to demonstrate that only glycine could label into chlorophyll. This makes $C$. velia the only known photosynthetic eukaryote to synthesize chlorophyll using glycine as a direct metabolic precursor. CvALAS contains a putative $\mathrm{N}$-terminal mitochondria-targeting peptide, so likely localizes to the mitochondrion as in other eukaryotes (Fig. $8 \mathrm{C})$. However, all the other putative C. velia heme synthesis enzymes contain $\mathrm{N}$-terminal leaders that resemble those found in apicoplast-targeting leaders of Apicomplexa, suggesting that the remainder of the $C$. velia heme (and chlorophyll) synthesis pathway occurs in the plastid (Fig. 8C).

To elucidate the evolutionary source of each enzyme, Koreny et al. performed extensive phylogenetic analyses, asking whether the $C$. velia and apicomplexan enzymes originate from the red alga that gave rise to the apicoplast, or from the proto-apicomplexan host cell. As expected (given that red algae lack an ALAS gene), C. velia and apicomplexan ALAS is derived from the host cell. Some of the apicoplast/plastid- localized enzymes-such as PBGS, PBGD, and UroS-likely derive from the red algal symbiont. Interestingly, Koreny et al. found that there were two or three paralogues of UroD, CPO, and $\mathrm{FeCH}$ in $\mathrm{C}$. velia, all of which contained plastid-targeting leader sequences. In the case of UroD and CPO, one paralogue is clearly descended from the algal symbiont, whereas the paralogue that is also found in Apicomplexa is likely derived from the host cell (Fig. 8C). The situation is slightly more complex for $\mathrm{FeCH}$, where one paralogue is clearly derived from the symbiont whereas the paralogue that is also found in Apicomplexa may have derived from a proteobacterium through lateral gene transfer either before or after symbiont acquisition. Curiously, apicomplexan PPO, which localizes to the mitochondrion of both P. falciparum and T. gondii, appears to derive from the red algal symbiont (Fig. 8D).

So how did the hybrid heme pathway of Apicomplexa and Chromera evolve? When the red algal symbiont was first acquired, the two tetrapyrrole pathways likely co-existed, as still occurs in Euglena (69). One pathway likely supplied heme to the mitochondrion, and the other supplied chlorophyll and heme to the plastid (Fig. 8A). The first step in the evolution toward the hybrid heme pathway of Apicomplexa was the loss of the plastid-based ALA synthesis pathway, with mitochondrially localized ALAS taking over supplying ALA to both the mitochondrion/cytosol and plastid tetrapyrrole synthesis pathways (Fig. 8B). The evolutionary rationale for losing the plastid ALA synthesis enzymes (GluTR and GSAAT) is not clear. When the symbiosis that led to the apicoplast first evolved, the ALAS gene would have been encoded in the host cell nucleus, whereas GluTR and GSA-AT would have been encoded in the nucleus of the red algal symbiont. ALA synthesis is the major rate-limiting (and therefore regulatory) step of tetrapyrrole biosynthesis in both animals and plants (see section on Regulating Heme Metabolism). One intriguing possibility is that making the symbiont dependent on hostderived ALA enabled the host cell to control photosynthesis in its recently enslaved symbiont. A simpler explanation is that redundancy in ALA synthesis pathways was rationalized without reduction in evolutionary fitness. Regardless of why it occurred, the loss of GluTR and GSA-AT requires the evolution of a mechanism to transport ALA from the mitochondrion to the apicoplast. PBGS (which uses ALA as a substrate) probably resides in the stroma (lumen) of the apicoplast, meaning that ALA must be exported across the two membranes of the mitochondrion and then imported across the four membranes bounding the apicoplast. A mechanism was already in place to export ALA from the mitochondrion, so this was no obstacle to the loss of GluTR and GSA-AT (Fig. $8 \mathrm{~B})$. But the conjoining of these pathways would have required novel apicoplast-localized transporters capable of importing ALA (160). The exchange of ALA between the mitochondrion and apicoplast may be facilitated by the close association of the apicoplast and mitochondrion in $P$. falciparum $(52,159)$, although such an intimate relationship between the organelles does not always occur in $T$. gondii (G.v.D., unpublished observations).

The fact that all remaining C. velia heme synthesis enzymes localize to the plastid suggests that the next step in the evolution of the hybrid heme pathway may have been the wholesale loss of the remaining cytosolic and mitochondrially localized enzymes (Fig. 8C). Interestingly, rather than being lost from the genome, some of these enzymes (UroD and 
FIG. 8. A proposed scheme for the evolution of the heme biosynthesis pathway of Apicomplexa. (A) When the ancestor of Apicomplexa first evolved a plastid, both the mitochondrial/cytosol and plastid pathways of tetrapyrrole synthesis co-existed, a situation found today in Euglena. (B) The evolution of transporters that allowed ALA import into the plastid (blue) facilitated the loss of the plastid ALA synthesis enzymes, with ALA now provided solely by the mitochondrion. (C) Evolving transporters that export heme from the plastid (blue) facilitated the loss of the cytosolic and terminal mitochondrial steps of the pathway. This is seen in Chromera velia today, where all the steps beyond ALA synthesis likely occur in the plastid. Most of the plastid enzymes in Chromera were derived from the plastidbearing symbiont (orange). Curiously, C. velia houses several enzymes that were likely acquired from the mitochondrial/cytosol pathway of the host cell (gray). (D) The loss of photosynthesis in Apicomplexa meant that tetrapyrroles were no longer required in the plastid. The terminal steps of heme biosynthesis then shifted back to the cytosol and mitochondrion, reflecting the pathway that exists in P. falciparum and T. gondiii today. The plastid (orange) and cytosolic (gray) ancestry of heme synthesis enzymes provides clues to the apparent shift in the localization of these enzymes during apicomplexan evolution (see text for details). To see this illustration in color the reader is referred to the Web version of this article at www.liebertonline.com/ars.

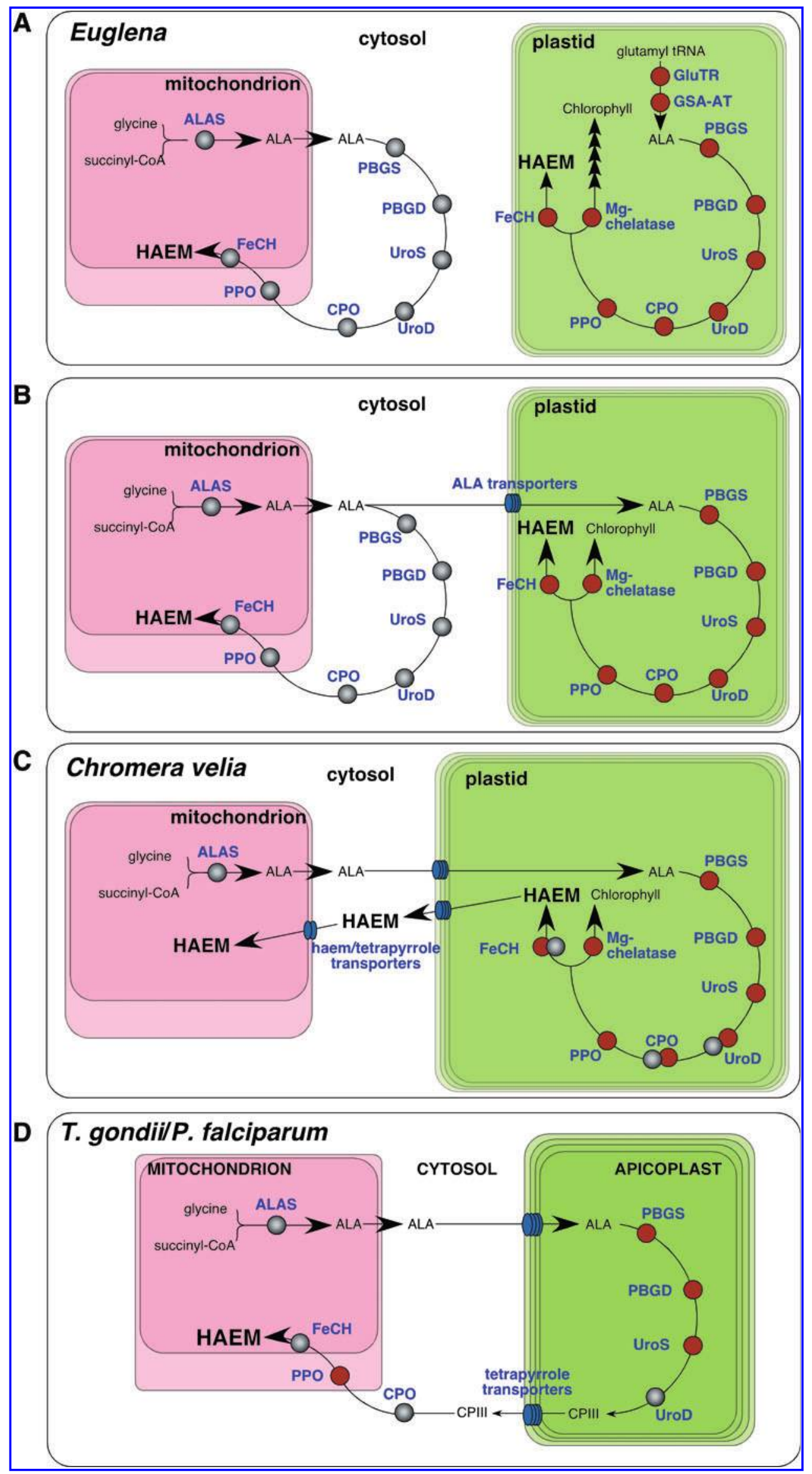


$\mathrm{CPO})$ were retargeted to the plastid where they apparently coexist with the plastid-derived version, although the rationale for maintaining multiple paralogues of a particular enzyme is not clear (Fig. 8C). A likely reason for the loss of the remaining cytosolic and mitochondrial steps of the pathway was that, like in plants, the plastid of the photosynthetic apicomplexan ancestor had the greatest need for tetrapyrroles. Evolving a mechanism to export already abundant heme from the plastid and import heme into the mitochondrion (Fig. 8C) would have made the cytosolic/mitochondrial heme pathway redundant.

The catalyst for the final stage in the evolution of the hybrid heme pathway was the loss of photosynthesis. With tetrapyrroles no longer required in the apicoplast, the mitochondrion became the major site of heme usage. Likely, the final three enzymes in the pathway were retargeted to the cytosol and mitochondrion to enable heme synthesis in the mitochondrion. In this scenario, CPIII represents the final product of the apicoplast steps of heme synthesis (Fig. 8D). A means of exporting CPIII from the apicoplast must have evolved to enable the final stages of heme pathway evolution. Given its structural similarity to heme, it is possible that the transporters that evolved to export heme from the apicoplast in the previous step could also transport CPIII.

An alternative scenario for the final stage of heme pathway evolution posits that the $C$. velia pathway represents a derived rather than an intermediate stage. In this scenario, the stage represented in Figure 8B featuring separate cytosolic/mitochondrion and plastid-localized pathways was maintained until after the divergence of Chromera from the apicomplexan lineage. At some point in the apicomplexan lineage, the first three cytosolic enzymes of the heme pathway became redundant and were lost, possibly as a result of the evolution of plastid transporters that could export CPIII from the organelle. The subsequent loss of photosynthesis in Apicomplexa meant that the final enzymes in the plastid pathway were no longer required, leading directly to the pathway seen in Figure 8D (160). It is unclear how long both pathways for tetrapyrrole synthesis co-existed in the apicomplexan/chromerid lineage. Intriguingly, Perkinsids, a nonphotosynthetic sister group to Apicomplexa and chromerids that nevertheless retain a plastid, may have lost the plastid pathway for tetrapyrrole synthesis $(36,70)$. Little is known about the localization of tetrapyrrole synthesis pathways in dinoflagellates, a photosynthetic sister group of Apicomplexa and chromerids, but some tetrapyrrole synthesis enzymes in these algae retain plastid signatures (70). Establishing the route of tetrapyrrole biosynthesis in dinoflagellates, perkinsids, and other early diverging sister groups of Apicomplexa likely holds the keys to unraveling the complex evolutionary steps that led to the "hybrid" pathway observed today.

\section{Heme scavenging in apicomplexan parasites}

Surprisingly, there are numerous Apicomplexa that lack the genes required for heme biosynthesis. These include Theileria, Babesia, and Cryptosporidium, all of which contain enzymes that require heme [Table $1 ;(79)]$. These organisms must therefore have an alternative source for heme. Organisms lacking heme synthesis pathways are not uncommon, and include numerous bacteria, trypanosomatid parasites, and the nematode worm $C$. elegans $(5,68,121)$. These organ- isms obtain their heme through numerous scavenging mechanisms. Gram-negative bacteria contain receptors on their outer membrane that bind heme or heme-containing proteins and traffic them into the periplasmic space $(5,152)$. Heme is then transported across the inner membrane, often via an ABC transporter. Heme acquisition in C. elegans involves the HRG proteins mentioned earlier (119).

Trypanosomatids are single-celled eukaryotic parasites that include the agents of African sleeping sickness (Trypanosoma brucei), Chagas disease (Trypanosoma cruzi), and leishmaniasis (Leishmania species). Much like Plasmodium, trypanosomatids have both insect and mammalian life stages. The mechanisms for heme acquisition in trypanosomatids are not well understood. In vitro growth of trypanosomatids requires the addition of heme to the growth medium (19), suggesting that these parasites can scavenge heme from their host organisms. Uptake of fluorescent heme analogues in T. cruzi is reduced in the presence of ABC transporter inhibitors, suggesting a role for these transporters in heme scavenging (77). ABC transporters may also have a role in heme scavenging in Leishmania, with mutants in one ABC transporter inhibiting the scavenging of heme bound to hemoglobin (16). Bloodstream forms of T. brucei express a receptor protein on their plasma membrane that binds to hemoglobinbound heme in the form of a haptoglobin/hemoglobin complex, and mediates the internalization of this complex by endocytosis (162). Notably, this receptor may also be the entry point into the parasite of trypanosome lytic factor (TLF), a high-density lipoprotein that contains haptoglobin-related protein bound to hemoglobin. TLF serves as a critical innate immune response that targets certain strains of T. brucei.

So how might Babesia, Theileria, and Cryptosporidium acquire heme from their host? Stages of the Babesia and Theileria lifecycles occur within heme-rich erythrocytes. Unlike Plasmodium, Babesia and Theileria do not endocytose vast quantities of hemoglobin from erythrocytes, so another mechanism of heme internalization might exist. Another life stage of Theileria occurs within the cytosol of leukocytes, where the parasite may have access to heme synthesized by the host cell, although it would presumably require plasma membrane transporters to do so. Cryptosporidium lives in an unusual extracytoplasmic compartment of gut epithelial cells. With very limited de novo metabolic capabilities, Cryptosporidium is adept at scavenging molecules such as sugars and nucleotides from its host (1). It is possible that Cryptosporidium can also scavenge heme, although with only one apparent hemerequiring protein (Table 1), the parasite's need for heme might be minimal. Clearly, there is still much to learn about how Apicomplexa lacking a heme synthesis pathway acquire their heme.

\section{Alternative mechanisms of heme acquisition in apicomplexan parasites}

Inhibitors of cytochrome $b$ such as atovaquone stop growth of erythrocytic and liver stages of Plasmodium as well as tachyzoite and tissue cyst stages of T. gondii $(6,103)$. This indicates that heme is required for parasite survival at various stages of the lifecycle in both P. falciparum and T. gondii. But is parasite heme synthesis the main supplier of heme during these stages? Surprisingly, in blood stages of $P$. falciparum, the answer appears to be no. The apicoplast of $P$. falciparum 
houses enzymes involved in several biosynthetic pathways beyond heme synthesis, including isoprenoid and fatty acid synthesis (120). Isoprenoid biosynthesis results in the formation of the molecule isopentenyl pyrophosphate (IPP) that is probably exported from the apicoplast and becomes an important component of several parasite molecules, including coenzyme Q, heme $a$, and dolichols (102). Derivatives of IPP also function in the prenylation of proteins such as Rabs to enable their association with cellular membranes. Fosmidomycin, a drug that targets IPP synthesis, kills blood-stage $P$. falciparum (59), suggesting that apicoplast IPP biosynthesis is essential for parasite survival in blood stages. In a recent study, Yeh and DeRisi supplemented the in vitro growth medium of blood-stage $P$. falciparum with exogenous IPP (176). They found that parasites were no longer sensitive to fosmidomycin, indicating that the addition of exogenous IPP overcame the requirement for isoprenoid synthesis in the apicoplast. Further, they found that treating parasites with inhibitors of apicoplast housekeeping processes results in the complete loss of apicoplasts from parasites, but that parasites lacking apicoplasts survived in the presence of IPP.

These experiments indicate that IPP synthesis is the only essential function of apicoplast metabolism during the erythrocytic cycle of $P$. falciparum. Genetic ablation of apicoplast fatty acid synthesis genes revealed that, indeed, this pathway is not essential in blood stages $(164,178)$. No gene knockout studies have yet been reported for heme synthesis genes, but, considering that apicoplast minus parasites are viable so long as they have a source of IPP, heme synthesis enzymes are very likely also not essential. So what is the alternative source for heme in blood stages of $P$. falciparum?

There is some evidence that the heme synthesis pathway of Plasmodium is not only built of parasite-encoded enzymes but also contains at least part of a parallel pathway constructed with the enzymes imported from the host erythrocytes (109). This so-called extrinsic heme synthesis pathway invokes the import of several heme biosynthesis proteins of the erythrocyte host cell into the parasite $(11,12)$. These enzymes then function in parasite heme synthesis. The best characterized of these imported enzymes is host cell PBGS, but also include $\mathrm{FeCH}, \mathrm{CPO}$, and possibly others $(11,12)$. Host cell ALAS is apparently not imported into the parasite. It remains unclear exactly how host cell enzymes are imported into the parasites, or how these enzymes are integrated into the heme synthesis pathway (e.g., is host cell FeCH imported into the mitochondrion, and if so, how?). There has been no direct test of the extrinsic pathway hypothesis for over a decade. One obvious way of testing the hypothesis is to generate genetic knockouts of parasite heme pathway enzymes, such as PBGS and $\mathrm{FeCH}$, and determine whether mutants can still generate heme from precursors such as glycine or ALA. If so, then the extrinsic pathway likely has a role in parasite heme synthesis. If not, then likely the extrinsic pathway has no role.

If imported host heme synthesis enzymes do not have a role in parasite heme synthesis in Plasmodium blood stages, and the parasite heme synthesis pathway is not essential for parasite growth, where do these parasites obtain their heme? One possibility is that, like in Theileria, Babesia, and possibly Cryptosporidium, Plasmodium blood stages are able to scavenge heme from their hosts. There are three possible routes of heme uptake in Plasmodium. The vast majority of heme released from hemoglobin in the parasite digestive vacuole is poly- merized as hemozoin (31). Nevertheless, the levels of heme taken into the digestive vacuole should be more than sufficient for parasite heme requirements. If parasites scavenge only minor proportion of heme released from hemoglobin digestion, then this may be enough to meet their requirements. Free heme also occurs in erythrocytes in concentrations of $\sim 1 \mu M$ (84). Heme could therefore be scavenged directly from the host cell by importing free heme through membrane receptors and transporters. A final route of entry could be heme derived directly from serum in the short time period between parasite egress from one host cell and the invasion of another. Intriguingly, a fluorescent analogue of heme (zinc-protoporphyrin IX) can be rapidly transported into the parasite cytosol in intraerythrocytic parasites (128), supporting the model of direct heme scavenging from the erythrocyte.

How might Plasmodium parasites scavenge heme from their hosts? Scavenging will likely involve membrane transporters. One requirement of these transporters is that they localize to the membrane where scavenging occurs, likely the parasite plasma membrane or digestive vacuole membrane. ABC transporters, which have a role in heme and tetrapyrrole import in a range of bacteria, mammals, and trypanosomatids (5, $16,72,73,77)$, are strong candidates. The $P$. falciparum genome encodes $\sim 16$ ABC-domain-containing proteins. Little is known about the native functions of these proteins. Curiously, one ABC transporter (PfMDR1) localizes to the digestive vacuole membrane and has a role in mediating parasite resistance to certain drugs (23). A second ABC transporter (PfMDR2) localizes, at least partly, to the plasma membrane, although this protein has been implicated in efflux of heavy metals from the parasite $(125,126)$. Another potential mechanism for scavenging heme is through exporting hemophore proteins that bind to free heme, as occurs in some bacteria (5). Receptors on the parasite surface may then bind to the hemophore and mediate heme transport into the parasite. No hemophores or hemophore receptors have been described in Plasmodium. Intriguingly, the heme-binding protein HRP2 is secreted into the host cell cytosol $(2,53)$ where it could conceivably function as a hemophore.

Determining the role of heme synthesis and scavenging in Apicomplexa that live inside nucleated host cells, such as $T$. gondii and liver-stage Plasmodium parasites, will also be particularly interesting. These parasites live inside host cells that have an active heme synthesis pathway, and parasites may be able to scavenge heme from these host cells. By analogy, intracellular stages of the T. cruzi and Leishmania lifecycles as well as some intracellular bacteria [such as the aphid symbiont Buchnera; (112)] live in nucleated cells and lack a complete heme synthesis pathway. These organisms likely scavenge heme from their hosts. Mycobacterium tuberculosis is a bacterium that lives inside macrophages. $M$. tuberculosis has its own heme synthesis pathway, but can also scavenge heme from its host using a hemophore-based mechanism (155). It is certainly possible that Apicomplexa that live inside nucleated cells can similarly scavenge heme. Genetic knockout and biochemical labeling experiments of parasites at these life stages will directly address these possibilities.

\section{Regulating Heme Metabolism}

The cytotoxic effects of free heme mean that organisms with an active heme synthesis pathway must tightly regulate this 
pathway to obtain a balance between generating enough required heme without generating harmful levels. Regulation of heme biosynthesis is well characterized in both animals and plants. In both cases, a major regulatory step of the pathway is the synthesis of ALA $(89,150)$. Regulation of mammalian ALAS is complex and occurs at multiple levels, likely reflecting the importance of this step. Mammals express two isoforms of ALAS - one is expressed exclusively in erythroid cells, where there is a large need of heme, and a second is expressed in all other cells. Both ALAS isoforms are regulated at a transcriptional level. In addition, mRNA of the erythroid form of ALAS contains an iron responsive element, a stemloop structure that is bound by iron regulatory protein (IRP) in iron limiting conditions (90). When bound, IRP inhibits ALAS translation, meaning that heme synthesis is downregulated in iron-poor conditions. Another unique ALAS regulation mechanism occurs during protein import into the mitochondrion. The N-terminal targeting leader of ALAS contains multiple cysteine-proline (CP) motifs that bind heme (78). When heme is bound, the targeting peptide of ALAS adopts a secondary structure that prevents its import into the mitochondrion. Thus, high levels of heme inhibit the initiation of further heme synthesis by keeping the enzyme away from its substrates. In mammalian cells, mRNA and protein turnover of ALAS is very rapid. Depending on organism and cell type, mRNA and protein half-life can both be as little as $1 \mathrm{~h}$ (60). Such a fast turnover enables heme synthesis to adjust rapidly in response to other regulatory mechanisms. Further, increased cellular heme levels can markedly decrease the halflife of both ALAS mRNA transcripts and protein $(30,151)$.

In plants, ALA synthesis is primarily regulated through GluTR activity. Since plants must control both heme and chlorophyll syntheses, GluTR activity can be regulated directly by heme, as well as by other mechanisms that apparently respond to chlorophyll precursor levels $(149,150)$. Although ALA production is a critical step in tetrapyrrole regulation in both plants and animals, it is important to note that there are several other points of regulation in the synthesis pathway. In addition to regulating tetrapyrrole synthesis, plants must also respond to the metabolic state of their plastids. Tetrapyrroles exported from plastids are critical retrograde signaling molecules in plants, where they regulate the expression of numerous genes in the plant nucleus (144). The exact identity of the retrograde signaling molecule(s) involved has been controversial, with $\mathrm{Mg}$-protoporphyrin and heme both proposed as candidates $(96,144,174)$.

Little is known about regulation of heme synthesis in Apicomplexa. These parasites often have complex lifecycles and requirements for heme probably vary substantially between different stages. This is particularly true for parasites such as Plasmodium that have life stages in both heme-rich and heme-poor niches. A study of ALAS and PBGS enzyme activity in blood stages of the simian malaria parasite Plasmodium knowlesi found that heme could partly inhibit activity of both enzymes (142), suggesting a possible direct means of regulating heme synthesis. Curiously, the mitochondrial targeting peptide of ALAS in both T. gondii and P. falciparum contains CP motifs that may bind heme (70). Indeed, in vitro import of $P$. falciparum ALAS into heterologous mitochondria can be inhibited by the addition of heme (163), suggesting that this unusual mechanism of ALAS regulation is conserved across a broad swath of eukaryotes. Nothing is known about the possible role of heme as a signaling molecule in Apicomplexa. It is perhaps surprising that Plasmodium bloodstage parasites still actively synthesize heme when there is an apparent alternative means of heme acquisition that should be more than sufficient to meet the requirements of the parasite $(147,176)$. It will be intriguing to determine whether there is cross-talk between heme synthesis, heme scavenging, and heme detoxification pathways in blood-stage Plasmodium parasites, all of which must be carefully regulated to ensure a sufficient supply of heme while at the same time negating potential toxic effects of this molecule.

\section{Conclusions}

Heme metabolism in apicomplexan parasites is complex, varied, and, in many aspects, understudied. Parasites utilize different mechanisms to acquire heme, both within and between different life stages. Further, there is surprising diversity among Apicomplexa in their means of acquiring heme. Drugs that target heme proteins such as cytochrome $b$, and drugs that target heme detoxification, are potent inhibitors of growth in numerous parasite species, indicating that heme metabolism is critical for parasite survival. Yet there are many aspects of heme detoxification, heme synthesis, heme scavenging, and heme usage in these parasites that are totally unknown. A better understanding of these processes, therefore, offers the potential to develop much needed therapeutic interventions against some of the most potent parasites on earth.

\section{Acknowledgments}

The authors are grateful to Ross Waller (University of Melbourne) for discussions and insightful comments on the article. This work was supported by grants from the Australian Research Council and University of Melbourne to G.v.D., and grants from the National Health and Medical Research Council and Australian Research Council to G.I.M. G.v.D. is a QEII Fellow of the Australian Research Council. G.I.M. is a Federation Fellow of the Australian Research Council and a Howard Hughes International Scholar.

\section{References}

1. Abrahamsen MS, Templeton TJ, Enomoto S, Abrahante JE, Zhu G, Lancto CA, Deng M, Liu C, Widmer G, Tzipori S, Buck GA, Xu P, Bankier AT, Dear PH, Konfortov BA, Spriggs HF, Iyer L, Anantharaman V, Aravind L, and Kapur V. Complete genome sequence of the apicomplexan, Cryptosporidium parvum. Science 304: 441-445, 2004.

2. Akompong T, Kadekoppala M, Harrison T, Oksman A, Goldberg DE, Fujioka H, Samuel BU, Sullivan D, and Haldar K. Trans expression of a Plasmodium falciparum histidine-rich protein II (HRPII) reveals sorting of soluble proteins in the periphery of the host erythrocyte and disrupts transport to the malarial food vacuole. L Biol Chem 277: 28923-28933, 2002.

3. Allen JF and Raven JA. Free-radical-induced mutation vs redox regulation: costs and benefits of genes in organelles. I Mol Evol 42: 482-492, 1996.

4. $\overline{\text { Allen JW}}$, Daltrop O, Stevens JM, and Ferguson SJ. C-type cytochromes: diverse structures and biogenesis systems pose evolutionary problems. Philos Trans $R$ Soc Lond B Biol Sci 358: 255-266, 2003. 
5. Anzaldi LL and Skaar EP. Overcoming the heme paradox: heme toxicity and tolerance in bacterial pathogens. Infect Immun 78: 4977-4989, 2010.

6. Araujo FG, Huskinson J, and Remington JS. Remarkable in vitro and in vivo activities of the hydroxynaphthoquinone 566C80 against tachyzoites and tissue cysts of Toxoplasma gondii. Antimicrob Agents Chemother 35: 293-299, 1991.

7. Badminton $\mathrm{MN}$ and Elder GH. Inherited disorders of haem synthesis: the human porphyrias. In: Tetrapyrroles: Birth, Life and Death, edited by Warren MJ and Smith AG. Austin: Landes Bioscience, 2009, pp. 89-100.

8. Balabaskaran Nina P, Morrisey JM, Ganesan SM, Ke H, Pershing AM, Mather MW, and Vaidya AB. ATP synthase complex of Plasmodium falciparum: dimeric assembly in mitochondrial membranes and resistance to genetic disruption. I Biol Chem 286: 41312-41322, 2011.

9. Beale SI and Castelfranco PA. ${ }^{14} \mathrm{C}$ incorporation from exogenous compounds into $\delta$-aminolevulinic acid by greening cucumber cotyledons. Biochem Biophys Res Commun 52: 143-149, 1973.

10. Biagini GA, Viriyavejakul P, O’Neill PM, Bray PG, and Ward SA. Functional characterization and target validation of alternative complex I of Plasmodium falciparum mitochondria. Antimicrob Agents Chemother 50: 1841-1851, 2006.

11. Bonday ZQ, Dhanasekaran S, Rangarajan PN, and Padmanaban G. Import of host delta-aminolevulinate dehydratase into the malarial parasite: identification of a new drug target. Nat Med 6: 898-903, 2000.

12. Bonday ZQ, Taketani S, Gupta PD, and Padmanaban G. Heme biosynthesis by the malarial parasite. Import of delta-aminolevulinate dehydrase from the host red cell. I Biol Chem 272: 21839-21846, 1997.

13. Bousejra-El Garah F, Wong MH, Amewu RK, Muangnoicharoen S, Maggs JL, Stigliani JL, Park BK, Chadwick J, Ward SA, and O'Neill PM. Comparison of the reactivity of antimalarial 1,2,4,5-tetraoxanes with 1,2,4-trioxolanes in the presence of ferrous iron salts, heme, and ferrous iron salts / phosphatidylcholine. I Med Chem 54: 6443-6455, 2011.

14. Boysen KE and Matuschewski K. Arrested oocyst maturation in Plasmodium parasites lacking type II NADH: ubiquinone dehydrogenase. J Biol Chem 286: 32661-32671, 2011.

15. Camadro JM, Chambon H, Jolles J, and Labbe P. Purification and properties of coproporphyrinogen oxidase from the yeast Saccharomyces cerevisiae. Eur J Biochem 156: 579587, 1986.

16. Campos-Salinas J, Cabello-Donayre M, Garcia-Hernandez R, Perez-Victoria I, Castanys S, Gamarro F, and PerezVictoria JM. A new ATP-binding cassette protein is involved in intracellular haem trafficking in Leishmania. Mol Microbiol 79: 1430-1444, 2011.

17. Capaldi RA and Aggeler R. Mechanism of the $F(1) F(0)$-type ATP synthase, a biological rotary motor. Trends Biochem Sci 27: 154-160, 2002.

18. Casals-Pascual C, Kai O, Cheung JO, Williams S, Lowe B, Nyanoti M, Williams TN, Maitland K, Molyneux M, Newton CR, Peshu N, Watt SM, and Roberts DJ. Suppression of erythropoiesis in malarial anemia is associated with hemozoin in vitro and in vivo. Blood 108: 2569-2577, 2006.

19. Chang KP and Trager W. Nutritional significance of symbiotic bacteria in two species of hemoflagellates. Science 183: 531-532, 1974.

20. Chen W, Dailey HA, and Paw BH. Ferrochelatase forms an oligomeric complex with mitoferrin- 1 and Abcb10 for erythroid heme biosynthesis. Blood 116: 628-630, 2010.
21. Cornah JE, Roper JM, Pal Singh D, and Smith AG. Measurement of ferrochelatase activity using a novel assay suggests that plastids are the major site of haem biosynthesis in both photosynthetic and non-photosynthetic cells of pea (Pisum sativum L.). Biochem I 362: 423-432, 2002.

22. Cornah JE and Smith AG. Transformation of uroporphyrinogen III into protohaem. In: Tetrapyrroles: Birth, Life and Death, edited by Warren MJ and Smith AG. Austin: Landes Bioscience, 2009, pp. 74-88.

23. Cowman AF, Karcz S, Galatis D, and Culvenor JG. A P-glycoprotein homologue of Plasmodium falciparum is localized on the digestive vacuole. LCell Biol 113: 10331042, 1991.

24. Crofts AR. The cytochrome $b c_{1}$ complex: function in the context of structure. Annu Rev Physiol 66: 689-733, 2004.

25. Dailey HA, Dailey TA, Wu CK, Medlock AE, Wang KF, Rose JP, and Wang BC. Ferrochelatase at the millennium: structures, mechanisms and [2Fe-2S] clusters. Cell Mol Life Sci 57: 1909-1926, 2000.

26. del Pilar Crespo M, Avery TD, Hanssen E, Fox E, Robinson TV, Valente P, Taylor DK, and Tilley L. Artemisinin and a series of novel endoperoxide antimalarials exert early effects on digestive vacuole morphology. Antimicrob Agents Chemother 52: 98-109, 2008.

27. Deybach JC, da Silva V, Grandchamp B, and Nordmann Y. The mitochondrial location of protoporphyrinogen oxidase. Eur J Biochem 149: 431-435, 1985.

28. Dhanasekaran S, Chandra NR, Chandrasekhar Sagar BK, Rangarajan PN, and Padmanaban G. Delta-aminolevulinic acid dehydratase from Plasmodium falciparum: indigenous versus imported. IBiol Chem 279: 6934-6942, 2004.

29. Ding M, Kwok LY, Schluter D, Clayton C, and Soldati D. The antioxidant systems in Toxoplasma gondii and the role of cytosolic catalase in defence against oxidative injury. $\underline{\mathrm{Mol}}$ Microbiol 51: 47-61, 2004.

30. Drew PD and Ades IZ. Regulation of the stability of chicken embryo liver delta-aminolevulinate synthase mRNA by hemin. Biochem Biophys Res Commun 162: 102-107, 1989.

31. Egan TJ, Combrinck JM, Egan J, Hearne GR, Marques HM, Ntenteni S, Sewell BT, Smith PJ, Taylor D, van Schalkwyk DA, and Walden JC. Fate of haem iron in the malaria parasite Plasmodium falciparum. Biochem I 365: 343-347, 2002.

32. Egan TJ, Mavuso WW, Ross DC, and Marques HM. Thermodynamic factors controlling the interaction of quinoline antimalarial drugs with ferriprotoporphyrin IX. I Inorg Biochem 68: 137-145, 1997.

33. Eggleson KK, Duffin KL, and Goldberg DE. Identification and characterization of falcilysin, a metallopeptidase involved in hemoglobin catabolism within the malaria parasite Plasmodium falciparum. I Biol Chem 274: 32411-32417, 1999.

34. Elder GH and Evans JO. Evidence that the coproporphyrinogen oxidase activity of rat liver is situated in the intermembrane space of mitochondria. Biochem I 172: 345-347, 1978.

35. Ferguson-Miller S and Babcock GT. Heme/Copper Terminal Oxidases. Chem Rev 96: 2889-2908, 1996.

36. Fernandez Robledo JA, Caler E, Matsuzaki M, Keeling PJ, Shanmugam D, Roos DS, and Vasta GR. The search for the missing link: a relic plastid in Perkinsus? Int J Parasitol 41: 1217-1229, 2011.

37. Francis SE, Sullivan DJ, Jr., and Goldberg DE. Hemoglobin metabolism in the malaria parasite Plasmodium falciparum. Annu Rev Microbiol 51: 97-123, 1997. 
38. Freitas TA, Hou $S$, and Alam M. The diversity of globincoupled sensors. FEBS Lett 552: 99-104, 2003.

39. Freitas TA, Hou S, Dioum EM, Saito JA, Newhouse J, Gonzalez G, Gilles-Gonzalez MA, and Alam M. Ancestral hemoglobins in Archaea. Proc Natl Acad Sci U S A 101: 6675-6680, 2004.

40. Fry M and Beesley JE. Mitochondria of mammalian Plasmodium spp. Parasitology 102 Pt 1: 17-26, 1991.

41. Gardner MJ, Hall N, Fung E, White O, Berriman M, Hyman RW, Carlton JM, Pain A, Nelson KE, Bowman S, Paulsen IT, James K, Eisen JA, Rutherford K, Salzberg SL, Craig A, Kyes S, Chan MS, Nene V, Shallom SJ, Suh B, Peterson J, Angiuoli S, Pertea M, Allen J, Selengut J, Haft D, Mather MW, Vaidya AB, Martin DM, Fairlamb AH, Fraunholz MJ, Roos DS, Ralph SA, McFadden GI, Cummings LM, Subramanian GM, Mungall C, Venter JC, Carucci DJ, Hoffman SL, Newbold C, Davis RW, Fraser CM, and Barrell B. Genome sequence of the human malaria parasite Plasmodium falciparum. Nature 419: 498-511, 2002.

42. Gibson KD, Laver WG, and Neuberger A. Initial stages in the biosynthesis of porphyrins. 2. The formation of delta-aminolaevulic acid from glycine and succinyl-coenzyme A by particles from chicken erythrocytes. Biochem J 70: 71-81, 1958.

43. Gluzman IY, Francis SE, Oksman A, Smith CE, Duffin KL, and Goldberg DE. Order and specificity of the Plasmodium falciparum hemoglobin degradation pathway. I Clin Invest 93: 1602-1608, 1994.

44. Grandchamp B, Phung N, and Nordmann Y. The mitochondrial localization of coproporphyrinogen III oxidase. Biochem J 176: 97-102, 1978.

45. Guerra CA, Gikandi PW, Tatem AJ, Noor AM, Smith DL, Hay SI, and Snow RW. The limits and intensity of Plasmodium falciparum transmission: implications for malaria control and elimination worldwide. PLoS Med 5: e38, 2008.

46. Hanssen E, Knoechel C, Klonis N, Abu-Bakar N, Deed S, LeGros M, Larabell C, and Tilley L. Cryo transmission Xray imaging of the malaria parasite, P. falciparum. I Struct Biol 173: 161-168, 2011.

47. Hawking F. Chloroquine resistance in Plasmodium berghei. Am J Trop Med Hyg 15: 287-293, 1966.

48. Hersleth HP, Ryde U, Rydberg P, Gorbitz CH, and Andersson KK. Structures of the high-valent metalion haem-oxygen intermediates in peroxidases, oxygenases and catalases. I Inorg Biochem 100: 460-476, 2006.

49. Hoang AN, Ncokazi KK, de Villiers KA, Wright DW, and Egan TJ. Crystallization of synthetic haemozoin (betahaematin) nucleated at the surface of lipid particles. Dalton Trans 39: 1235-1244, 2010.

50. Hoang AN, Sandlin RD, Omar A, Egan TJ, and Wright DW. The neutral lipid composition present in the digestive vacuole of Plasmodium falciparum concentrates heme and mediates beta-hematin formation with an unusually low activation energy. Biochemistry 49: 10107-10116, 2010.

51. Hohmann-Marriott MF and Blankenship RE. Evolution of photosynthesis. Annu Rev Plant Biol 62: 515-548, 2011.

52. Hopkins J, Fowler R, Krishna S, Wilson I, Mitchell G, and Bannister L. The plastid in Plasmodium falciparum asexual blood stages: a three-dimensional ultrastructural analysis. Protist 150: 283-295, 1999.

53. Howard RJ, Uni S, Aikawa M, Aley SB, Leech JH, Lew AM, Wellems TE, Rener J, and Taylor DW. Secretion of a malarial histidine-rich protein (PfHRP II) from Plasmodium falciparuminfected erythrocytes. I Cell Biol 103: 1269-1277, 1986.

54. Huttemann M, Pecina P, Rainbolt M, Sanderson TH, Kagan VE, Samavati L, Doan JW, and Lee I. The multiple func- tions of cytochrome $c$ and their regulation in life and death decisions of the mammalian cell: from respiration to apoptosis. Mitochondrion 11: 369-381, 2011.

55. Illis L. On Porphyria and the Aetiology of Werwolves. Proc R Soc Med 57: 23-26, 1964.

56. Jacobs JM and Jacobs NJ. Porphyrin Accumulation and Export by Isolated Barley (Hordeum vulgare) Plastids (Effect of Diphenyl Ether Herbicides). Plant Physiol 101: 1181-1187, 1993.

57. Jani D, Nagarkatti R, Beatty W, Angel R, Slebodnick C, Andersen J, Kumar S, and Rathore D. HDP-a novel heme detoxification protein from the malaria parasite. $\underline{P L O S P a}-$ thog 4: e1000053, 2008.

58. Janouskovec J, Horak A, Obornik M, Lukes J, and Keeling PJ. A common red algal origin of the apicomplexan, dinoflagellate, and heterokont plastids. Proc Natl Acad Sci U S A 107: 10949-10954, 2010.

59. Jomaa H, Wiesner J, Sanderbrand S, Altincicek B, Weidemeyer C, Hintz M, Turbachova I, Eberl M, Zeidler J, Lichtenthaler HK, Soldati D, and Beck E. Inhibitors of the nonmevalonate pathway of isoprenoid biosynthesis as antimalarial drugs. Science 285: 1573-1576, 1999.

60. Jordan PM. The biosynthesis of 5-aminolaevulinic acid and its transformation into uroporphyrinogen III. In: Biosynthesis of Tetrapyrroles, edited by Jordan PM. Amsterdam: Elsevier, 1991, pp. 1-66.

61. Kappler U. Bacterial sulfite-oxidizing enzymes. Biochim Biophys Acta 1807: 1-10, 2011.

62. Kehr S, Sturm N, Rahlfs S, Przyborski JM, and Becker K. Compartmentation of redox metabolism in malaria parasites. PLoS Pathog 6: e1001242, 2010.

63. Kessl JJ, Lange BB, Merbitz-Zahradnik T, Zwicker K, Hill P, Meunier B, Palsdottir H, Hunte C, Meshnick S, and Trumpower BL. Molecular basis for atovaquone binding to the cytochrome $b c_{1}$ complex. J Biol Chem 278: 31312-31318, 2003.

64. Kikuchi G, Kumar A, Talmage P, and Shemin D. The enzymatic synthesis of delta-aminolevulinic acid. $\underline{\text { Biol Chem }}$ 233: 1214-1219, 1958.

65. Klemba M, Gluzman I, and Goldberg DE. A Plasmodium falciparum dipeptidyl aminopeptidase I participates in vacuolar hemoglobin degradation. I Biol Chem 279: 4300043007, 2004.

66. Klonis N, Crespo-Ortiz MP, Bottova I, Abu-Bakar N, Kenny S, Rosenthal PJ, and Tilley L. Artemisinin activity against Plasmodium falciparum requires hemoglobin uptake and digestion. Proc Natl Acad Sci U S A 108: 11405-11410, 2011.

67. Kohler S, Delwiche CF, Denny PW, Tilney LG, Webster P, Wilson RJ, Palmer JD, and Roos DS. A plastid of probable green algal origin in Apicomplexan parasites. Science 275: 1485-1489, 1997.

68. Koreny L, Lukes J, and Obornik M. Evolution of the haem synthetic pathway in kinetoplastid flagellates: an essential pathway that is not essential after all? Int J Parasitol 40: 149156, 2010.

69. Koreny L and Obornik M. Sequence evidence for the presence of two tetrapyrrole pathways in Euglena gracilis. Genome Biol Evol 3: 359-364, 2011.

70. Koreny L, Sobotka R, Janouskovec J, Keeling PJ, and Obornik M. Tetrapyrrole Synthesis of Photosynthetic Chromerids Is Likely Homologous to the Unusual Pathway of Apicomplexan Parasites. Plant Cell 23: 3454-3462, 2011.

71. Kranz R, Lill R, Goldman B, Bonnard G, and Merchant S. Molecular mechanisms of cytochrome $c$ biogenesis: three distinct systems. Mol Microbiol 29: 383-396, 1998. 
72. Krishnamurthy P, Xie T, and Schuetz JD. The role of transporters in cellular heme and porphyrin homeostasis. Pharmacol Ther 114: 345-358, 2007.

73. Krishnamurthy PC, Du G, Fukuda Y, Sun D, Sampath J, Mercer KE, Wang J, Sosa-Pineda B, Murti KG, and Schuetz JD. Identification of a mammalian mitochondrial porphyrin transporter. Nature 443: 586-589, 2006.

74. Kumar S and Bandyopadhyay U. Free heme toxicity and its detoxification systems in human. Toxicol Lett 157: 175188, 2005.

75. LaGier MJ, Tachezy J, Stejskal F, Kutisova K, and Keithly JS. Mitochondrial-type iron-sulfur cluster biosynthesis genes (IscS and IscU) in the apicomplexan Cryptosporidium parvum. Microbiology 149: 3519-3530, 2003.

76. Langreth SG, Nguyen-Dinh P, and Trager W. Plasmodium falciparum: merozoite invasion in vitro in the presence of chloroquine. Exp Parasitol 46: 235-238, 1978.

77. Lara FA, Sant'anna C, Lemos D, Laranja GA, Coelho MG, Reis Salles I, Michel A, Oliveira PL, Cunha ESN, Salmon D, and Paes MC. Heme requirement and intracellular trafficking in Trypanosoma cruzi epimastigotes. Biochem Biophys Res Commun 355: 16-22, 2007.

78. Lathrop JT and Timko MP. Regulation by heme of mitochondrial protein transport through a conserved amino acid motif. Science 259: 522-525, 1993.

79. Lau AO. An overview of the Babesia, Plasmodium and Theileria genomes: a comparative perspective. Mol Biochem Parasitol 164: 1-8, 2009.

80. Lecomte JT, Vuletich DA, and Lesk AM. Structural divergence and distant relationships in proteins: evolution of the globins. Curr Opin Struct Biol 15: 290-301, 2005.

81. Lermontova I, Kruse E, Mock HP, and Grimm B. Cloning and characterization of a plastidal and a mitochondrial isoform of tobacco protoporphyrinogen IX oxidase. Proc Natl Acad Sci U S A 94: 8895-8900, 1997.

82. Lin SS, Gross U, and Bohne W. Two internal type II NADH dehydrogenases of Toxoplasma gondii are both required for optimal tachyzoite growth. Mol Microbiol 82: 209-221, 2011.

83. Liu J, Istvan ES, Gluzman IY, Gross J, and Goldberg DE. Plasmodium falciparum ensures its amino acid supply with multiple acquisition pathways and redundant proteolytic enzyme systems. Proc Natl Acad Sci U S A 103: 8840-8845, 2006.

84. Liu SC, Zhai S, and Palek J. Detection of hemin release during hemoglobin S denaturation. Blood 71: 1755-1758, 1988.

85. Mack SR, Samuels S, and Vanderberg JP. Hemolymph of Anopheles stephensi from noninfected and Plasmodium berghei-infected mosquitoes. 3. Carbohydrates. I Parasitol 65: 217-221, 1979.

86. Macomber PB and Sprinz H. Morphological effects of chloroquine on Plasmodium berghei in mice. Nature 214: 937939, 1967.

87. Maines MD and Gibbs PE. 30 some years of heme oxygenase: from a "molecular wrecking ball" to a "mesmerizing" trigger of cellular events. Biochem Biophys Res Commun 338: 568-577, 2005.

88. McFadden GI, Reith ME, Munholland J, and Lang-Unnasch N. Plastid in human parasites. Nature 381: 482, 1996.

89. Medlock AE and Dailey HA. Regulation of mammalian heme synthesis. In: Tetrapyrroles: Birth, Life and Death, edited by Warren MJ and Smith AG. Austin: Landes Bioscience, 2009, pp. 116-127.

90. Melefors O, Goossen B, Johansson HE, Stripecke R, Gray NK, and Hentze MW. Translational control of 5-aminole- vulinate synthase mRNA by iron-responsive elements in erythroid cells. L Biol Chem 268: 5974-5978, 1993.

91. Meunier B and Robert A. Heme as trigger and target for trioxane-containing antimalarial drugs. Acc Chem Res 43: 1444-1451, 2010.

92. Miller LH, Good MF, and Milon G. Malaria pathogenesis. Science 264: 1878-1883, 1994.

93. Mogi T and Kita K. Identification of mitochondrial Complex II subunits SDH3 and SDH4 and ATP synthase subunits a and b in Plasmodium spp. Mitochondrion 9: 443-453, 2009.

94. Moore RB, Obornik M, Janouskovec J, Chrudimsky T, Vancova M, Green DH, Wright SW, Davies NW, Bolch CJ, Heimann K, Slapeta J, Hoegh-Guldberg O, Logsdon JM, and Carter DA. A photosynthetic alveolate closely related to apicomplexan parasites. Nature 451: 959-963, 2008.

95. Moraes CT, Diaz F, and Barrientos A. Defects in the biosynthesis of mitochondrial heme $\mathrm{c}$ and heme $\mathrm{a}$ in yeast and mammals. Biochim Biophys Acta 1659: 153-159, 2004.

96. Moulin M, McCormac AC, Terry MJ, and Smith AG. Tetrapyrrole profiling in Arabidopsis seedlings reveals that retrograde plastid nuclear signaling is not due to $\mathrm{Mg}$ protoporphyrin IX accumulation. Proc Natl Acad Sci U S A 105: 15178-15183, 2008.

97. Nagaraj VA, Arumugam R, Chandra NR, Prasad D, Rangarajan PN, and Padmanaban G. Localisation of Plasmodium falciparum uroporphyrinogen III decarboxylase of the hemebiosynthetic pathway in the apicoplast and characterisation of its catalytic properties. Int J Parasitol 39: 559-568, 2009.

98. Nagaraj VA, Arumugam R, Gopalakrishnan B, Jyothsna YS, Rangarajan PN, and Padmanaban G. Unique properties of Plasmodium falciparum porphobilinogen deaminase. I Biol Chem 283: 437-444, 2008.

99. Nagaraj VA, Arumugam R, Prasad D, Rangarajan PN, and Padmanaban G. Protoporphyrinogen IX oxidase from Plasmodium falciparum is anaerobic and is localized to the mitochondrion. Mol Biochem Parasitol 174: 44-52, 2010.

100. Nagaraj VA, Prasad D, Arumugam R, Rangarajan PN, and Padmanaban G. Characterization of coproporphyrinogen III oxidase in Plasmodium falciparum cytosol. Parasitol Int 59: 121-127, 2010.

101. Nagaraj VA, Prasad D, Rangarajan PN, and Padmanaban G. Mitochondrial localization of functional ferrochelatase from Plasmodium falciparum. Mol Biochem Parasitol 168: 109112, 2009.

102. Nair SC and Striepen B. What do human parasites do with a chloroplast anyway? PLoS Biol 9: e1001137, 2011.

103. Nam TG, McNamara CW, Bopp S, Dharia NV, Meister S, Bonamy GM, Plouffe DM, Kato N, McCormack S, Bursulaya B, Ke H, Vaidya AB, Schultz PG, and Winzeler EA. A Chemical Genomic Analysis of Decoquinate, a Plasmodium falciparum Cytochrome $b$ Inhibitor. ACS Chem Biol 6: 1214$1222,2011$.

104. O'Callaghan KM, Ayllon V, O'Keeffe J, Wang Y, Cox OT, Loughran G, Forgac M, and O'Connor R. Heme-binding protein HRG-1 is induced by insulin-like growth factor I and associates with the vacuolar $\mathrm{H}^{+}$-ATPase to control endosomal $\mathrm{pH}$ and receptor trafficking. I Biol Chem 285: 381-391, 2010.

105. O'Neill PM and Posner GH. A medicinal chemistry perspective on artemisinin and related endoperoxides. $\underline{\mathrm{IMed}}$ Chem 47: 2945-2964, 2004.

106. Okada K. The novel heme oxygenase-like protein from Plasmodium falciparum converts heme to bilirubin IXalpha in the apicoplast. FEBS Lett 583: 313-319, 2009. 
107. Orjih AU, Banyal HS, Chevli R, and Fitch CD. Hemin lyses malaria parasites. Science 214: 667-669, 1981.

108. Osafune T and Schiff JA. W10BSmL, a mutant of Euglena gracilis var. bacillaris lacking plastids. Exp Cell Res 148: 530535, 1983.

109. Padmanaban G, Nagaraj VA, and Rangarajan PN. An alternative model for heme biosynthesis in the malarial parasite. Trends Biochem Sci 32: 443-449, 2007.

110. Pagola S, Stephens PW, Bohle DS, Kosar AD, and Madsen SK. The structure of malaria pigment beta-haematin. Nature 404: 307-310, 2000.

111. Painter HJ, Morrisey JM, Mather MW, and Vaidya AB. Specific role of mitochondrial electron transport in bloodstage Plasmodium falciparum. Nature 446: 88-91, 2007.

112. Panek $\mathrm{H}$ and $\mathrm{O}^{\prime}$ Brian MR. A whole genome view of prokaryotic haem biosynthesis. Microbiology 148: 2273-2282, 2002.

113. Perkins DJ, Were T, Davenport GC, Kempaiah P, Hittner JB, and Ong'echa JM. Severe malarial anemia: innate immunity and pathogenesis. Int J Biol Sci 7: 1427-1442, 2011.

114. Peters W. Pigment Formation and Nuclear Division in Chloroquine-Resistant Malaria Parasites (Plasmodium Berghei, Vincke and Lips, 1948). Nature 203: 1290-1291, 1964.

115. Pfanner $\mathrm{N}$ and Truscott KN. Powering mitochondrial protein import. Nat Struct Biol 9: 234-236, 2002.

116. Pisciotta JM, Coppens I, Tripathi AK, Scholl PF, Shuman J, Bajad S, Shulaev V, and Sullivan DJ, Jr. The role of neutral lipid nanospheres in Plasmodium falciparum haem crystallization. Biochem J 402: 197-204, 2007.

117. Qiu A, Jansen M, Sakaris A, Min SH, Chattopadhyay S, Tsai E, Sandoval C, Zhao R, Akabas MH, and Goldman ID. Identification of an intestinal folate transporter and the molecular basis for hereditary folate malabsorption. Cell 127: 917-928, 2006

118. Ragheb D, Dalal S, Bompiani KM, Ray WK, and Klemba M. Distribution and biochemical properties of an M1-family aminopeptidase in Plasmodium falciparum indicate a role in vacuolar hemoglobin catabolism. I Biol Chem 286: 27255 27265, 2011.

119. Rajagopal A, Rao AU, Amigo J, Tian M, Upadhyay SK, Hall C, Uhm S, Mathew MK, Fleming MD, Paw BH, Krause M, and Hamza I. Haem homeostasis is regulated by the conserved and concerted functions of HRG-1 proteins. Nature 453: 1127-1131, 2008.

120. Ralph SA, van Dooren GG, Waller RF, Crawford MJ, Fraunholz MJ, Foth BJ, Tonkin CJ, Roos DS, and McFadden GI. Tropical infectious diseases: Metabolic maps and functions of the Plasmodium falciparum apicoplast. Nat Rev Microbiol 2: 203-216, 2004.

121. Rao AU, Carta LK, Lesuisse E, and Hamza I. Lack of heme synthesis in a free-living eukaryote. Proc Natl Acad Sci U S A 102: 4270-4275, 2005.

122. Raven EL, Lad L, Sharp KH, Mewies M, and Moody PC. Defining substrate specificity and catalytic mechanism in ascorbate peroxidase. Biochem Soc Symp: 27-38, 2004.

123. Riordan CE, Ault JG, Langreth SG, and Keithly JS. Cryptosporidium paroum Cpn60 targets a relict organelle. Curr Genet 44: 138-147, 2003.

124. Roberts CW, Roberts F, Henriquez FL, Akiyoshi D, Samuel BU, Richards TA, Milhous W, Kyle D, McIntosh L, Hill GC, Chaudhuri M, Tzipori S, and McLeod R. Evidence for mitochondrial-derived alternative oxidase in the apicomplexan parasite Cryptosporidium paroum: a potential antimicrobial agent target. Int I Parasitol 34: 297-308, 2004.
125. Rosenberg E, Litus I, Schwarzfuchs N, Sinay R, Schlesinger P, Golenser J, Baumeister S, Lingelbach K, and Pollack Y. pfmdr2 confers heavy metal resistance to Plasmodium falciparum. I Biol Chem 281: 27039-27045, 2006.

126. Rubio JP and Cowman AF. Plasmodium falciparum: the pfmdr2 protein is not overexpressed in chloroquineresistant isolates of the malaria parasite. Exp Parasitol 79: 137-147, 1994.

127. Rutter J, Winge DR, and Schiffman JD. Succinate dehydrogenase - Assembly, regulation and role in human disease. Mitochondrion 10: 393-401, 2010.

128. Sartorello R, Budu A, Bagnaresi P, Fernandes CA, Sato PM, Bueno VB, Fontes MR, Oliveira PL, Paiva-Silva GO, Alves SV, Netto LE, Catalani LH, and Garcia CR. In vivo uptake of a haem analogue Zn protoporphyrin IX by the human malaria parasite P. falciparum-infected red blood cells. Cell Biol Int 34: 859-865, 2010.

129. Sato S, Clough B, Coates L, and Wilson RJ. Enzymes for heme biosynthesis are found in both the mitochondrion and plastid of the malaria parasite Plasmodium falciparum. Protist 155: 117-125, 2004.

130. Sato S and Wilson RJ. The genome of Plasmodium falciparum encodes an active delta-aminolevulinic acid dehydratase. Curr Genet 40: 391-398, 2002.

131. Schenkman JB and Jansson I. The many roles of cytochrome $b_{5}$. Pharmacol Ther 97: 139-152, 2003.

132. Schultz IJ, Chen C, Paw BH, and Hamza I. Iron and porphyrin trafficking in heme biogenesis. I Biol Chem 285: 26753-26759, 2010.

133. Shanmugam D, Wu B, Ramirez U, Jaffe EK, and Roos DS. Plastid-associated porphobilinogen synthase from Toxoplasma gondii: kinetic and structural properties validate therapeutic potential. L Biol Chem 285: 22122-22131, 2010.

134. Shayeghi M, Latunde-Dada GO, Oakhill JS, Laftah AH, Takeuchi K, Halliday N, Khan Y, Warley A, McCann FE, Hider RC, Frazer DM, Anderson GJ, Vulpe CD, Simpson $\mathrm{RJ}$, and McKie AT. Identification of an intestinal heme transporter. Cell 122: 789-801, 2005.

135. Shemin D and Rittenberg D. The utilization of glycine for the synthesis of a porphyrin. J Biol Chem 159: 567-568, 1945.

136. Shio MT, Kassa FA, Bellemare MJ, and Olivier M. Innate inflammatory response to the malarial pigment hemozoin. Microbes Infect 12: 889-899, 2010.

137. Sibley LD, Lawson R, and Weidner E. Superoxide dismutase and catalase in Toxoplasma gondii. Mol Biochem Parasitol 19: 83-87, 1986.

138. Slater AF and Cerami A. Inhibition by chloroquine of a novel haem polymerase enzyme activity in malaria trophozoites. Nature 355: 167-169, 1992.

139. Smilkstein MJ, Forquer I, Kanazawa A, Kelly JX, Winter RW, Hinrichs DJ, Kramer DM, and Riscoe MK. A drug-selected Plasmodium falciparum lacking the need for conventional electron transport. Mol Biochem Parasitol 159: 64-68, 2008.

140. Srivastava IK, Morrisey JM, Darrouzet E, Daldal F, and Vaidya $\mathrm{AB}$. Resistance mutations reveal the atovaquonebinding domain of cytochrome $b$ in malaria parasites. $\underline{\mathrm{Mol}}$ Microbiol 33: 704-711, 1999.

141. Srivastava IK, Rottenberg H, and Vaidya AB. Atovaquone, a broad spectrum antiparasitic drug, collapses mitochondrial membrane potential in a malarial parasite. I Biol Chem 272: 3961-3966, 1997.

142. Srivastava P and Pandey VC. Heme synthesizing enzymes of Plasmodium knowlesi: a simian malaria parasite. Exp Parasitol 88: 60-63, 1998. 
143. Storbeck S, Rolfes S, Raux-Deery E, Warren MJ, Jahn D, and Layer G. A novel pathway for the biosynthesis of heme in Archaea: genome-based bioinformatic predictions and experimental evidence. Archaea 2010: 175050, 2010.

144. Strand A, Asami T, Alonso J, Ecker JR, and Chory J. Chloroplast to nucleus communication triggered by accumulation of Mg-protoporphyrinIX. Nature 421: 79-83, 2003.

145. Sullivan DJ, Jr., Gluzman IY, and Goldberg DE. Plasmodium hemozoin formation mediated by histidine-rich proteins. Science 271: 219-222, 1996.

146. Sullivan DJ, Jr., Gluzman IY, Russell DG, and Goldberg DE. On the molecular mechanism of chloroquine's antimalarial action. Proc Natl Acad Sci U S A 93: 11865-11870, 1996.

147. Surolia N and Padmanaban G. de novo biosynthesis of heme offers a new chemotherapeutic target in the human malarial parasite. Biochem Biophys Res Commun 187: 744-750, 1992.

148. Suzuki T, Hashimoto T, Yabu Y, Kido Y, Sakamoto K, Nihei C, Hato M, Suzuki S, Amano Y, Nagai K, Hosokawa T, Minagawa N, Ohta N, and Kita K. Direct evidence for cyanide-insensitive quinol oxidase (alternative oxidase) in apicomplexan parasite Cryptosporidium parvum: phylogenetic and therapeutic implications. Biochem Biophys Res Commun 313: 1044-1052, 2004.

149. Tanaka $\mathrm{R}$ and Tanaka A. Tetrapyrrole biosynthesis in higher plants. Annu Rev Plant Biol 58: 321-346, 2007.

150. Terry MJ and Smith AG. Regulation of tetrapyrrole synthesis in higher plants. In: Tetrapyrroles: Birth, Life and Death, edited by Warren MJ and Smith AG. Austin: Landes Bioscience, 2009, pp. 250-262.

151. Tian Q, Li T, Hou W, Zheng J, Schrum LW, and Bonkovsky HL. Lon peptidase 1 (LONP1)-dependent breakdown of mitochondrial 5-aminolevulinic acid synthase protein by heme in human liver cells. L Biol Chem 286: 26424-26430, 2011.

152. Tong $\mathrm{Y}$ and Guo M. Bacterial heme-transport proteins and their heme-coordination modes. Arch Biochem Biophys 481: $1-15,2009$.

153. Tonhosolo R, Gabriel HB, Matsumura MY, Cabral FJ, Yamamoto MM, D'Alexandri FL, Sussmann RA, Belmonte R, Peres VJ, Crick DC, Wunderlich G, Kimura EA, and Katzin AM. Intraerythrocytic stages of Plasmodium falciparum biosynthesize menaquinone. FEBS Lett 584: 4761-4768, 2010.

154. Tsukihara T, Aoyama H, Yamashita E, Tomizaki T, Yamaguchi H, Shinzawa-Itoh K, Nakashima R, Yaono R, and Yoshikawa $S$. The whole structure of the 13-subunit oxidized cytochrome $c$ oxidase at 2.8 A. Science 272: 1136-1144, 1996.

155. Tullius MV, Harmston CA, Owens CP, Chim N, Morse RP, McMath LM, Iniguez A, Kimmey JM, Sawaya MR, Whitelegge JP, Horwitz MA, and Goulding CW. Discovery and characterization of a unique mycobacterial heme acquisition system. Proc Natl Acad Sci U S A 108: 5051-5056, 2011.

156. Uyemura SA, Luo $S$, Moreno SN, and Docampo R. Oxidative phosphorylation, $\mathrm{Ca}(2+)$ transport, and fatty acidinduced uncoupling in malaria parasites mitochondria. I Biol Chem 275: 9709-9715, 2000.

157. Uyemura SA, Luo S, Vieira M, Moreno SN, and Docampo R. Oxidative phosphorylation and rotenone-insensitive malateand NADH-quinone oxidoreductases in Plasmodium yoelii yoelii mitochondria in situ. L Biol Chem 279: 385-393, 2004.

158. Van Bogaert IN, Groeneboer S, Saerens K, and Soetaert W. The role of cytochrome P450 monooxygenases in microbial fatty acid metabolism. FEBS I 278: 206-221, 2011.

159. van Dooren GG, Marti M, Tonkin CJ, Stimmler LM, Cowman AF, and McFadden GI. Development of the endoplasmic reticulum, mitochondrion and apicoplast during the asexual life cycle of Plasmodium falciparum. Mol Microbiol 57: 405-419, 2005.

160. van Dooren GG, Stimmler LM, and McFadden GI. Metabolic maps and functions of the Plasmodium mitochondrion. FEMS Microbiol Rev 30: 596-630, 2006.

161. Vander Jagt DL, Hunsaker LA, and Campos NM. Characterization of a hemoglobin-degrading, low molecular weight protease from Plasmodium falciparum. Mol Biochem Parasitol 18: 389-400, 1986.

162. Vanhollebeke B, De Muylder G, Nielsen MJ, Pays A, Tebabi P, Dieu M, Raes M, Moestrup SK, and Pays E. A haptoglobin-hemoglobin receptor conveys innate immunity to Trypanosoma brucei in humans. Science 320: 677-681, 2008.

163. Varadharajan S, Dhanasekaran S, Bonday ZQ, Rangarajan PN, and Padmanaban G. Involvement of delta-aminolaevulinate synthase encoded by the parasite gene in de novo haem synthesis by Plasmodium falciparum. Biochem I 367: 321-327, 2002.

164. Vaughan AM, O'Neill MT, Tarun AS, Camargo N, Phuong TM, Aly AS, Cowman AF, and Kappe SH. Type II fatty acid synthesis is essential only for malaria parasite late liver stage development. Cell Microbiol 11: 506-520, 2009.

165. Vercesi AE, Rodrigues CO, Uyemura SA, Zhong L, and Moreno SN. Respiration and oxidative phosphorylation in the apicomplexan parasite Toxoplasma gondii. L Biol Chem 273: 31040-31047, 1998.

166. Vernon DI and Walker I. Tetrapyrroles in photodynaminc therapy. In: Tetrapyrroles: Birth, Life and Death, edited by Warren MJ and Smith AG. Austin: Landes Bioscience, 2009, pp. $128-148$.

167. Vinogradov SN and Moens L. Diversity of globin function: enzymatic, transport, storage, and sensing. IBiol Chem 283: 8773-8777, 2008.

168. von Schubert C, Xue G, Schmuckli-Maurer J, Woods KL, Nigg EA, and Dobbelaere DA. The transforming parasite Theileria co-opts host cell mitotic and central spindles to persist in continuously dividing cells. PLoS Biol 8: e1000499, 2010.

169. Wang J, Huang L, Li J, Fan Q, Long Y, Li Y, and Zhou B. Artemisinin directly targets malarial mitochondria through its specific mitochondrial activation. PLoS One 5: e9582, 2010.

170. Warhurst DC and Hockley DJ. Mode of action of chloroquine on Plasmodium berghei and P. cynomolgi. Nature 214: 935-936, 1967.

171. Weinstein JD and Beale SI. Separate physiological roles and subcellular compartments for two tetrapyrrole biosynthetic pathways in Euglena gracilis. J Biol Chem 258: 6799-6807, 1983.

172. Wilson CM, Smith AB, and Baylon RV. Characterization of the delta-aminolevulinate synthase gene homologue in $P$. falciparum. Mol Biochem Parasitol 79: 135-140, 1996.

173. Wilson RJ, Denny PW, Preiser PR, Rangachari K, Roberts K, Roy A, Whyte A, Strath M, Moore DJ, Moore PW, and Williamson DH. Complete gene map of the plastid-like DNA of the malaria parasite Plasmodium falciparum. L Mol Biol 261: 155-172, 1996.

174. Woodson JD, Perez-Ruiz JM, and Chory J. Heme synthesis by plastid ferrochelatase I regulates nuclear gene expression in plants. Curr Biol 21: 897-903, 2011.

175. Wu B. Heme Biosynthetic Pathway in Apicomplexan Parasites. Philadelphia: University of Pennsylvania, 2006.

176. Yeh E and DeRisi JL. Chemical rescue of malaria parasites lacking an apicoplast defines organelle function in bloodstage Plasmodium falciparum. PLoS Biol 9: e1001138, 2011.

177. Yoshikawa S, Muramoto K, and Shinzawa-Itoh K. Protonpumping mechanism of cytochrome $c$ oxidase. Annu Rev Biophys 40: 205-223, 2011. 
178. Yu M, Kumar TR, Nkrumah LJ, Coppi A, Retzlaff S, Li CD, Kelly BJ, Moura PA, Lakshmanan V, Freundlich JS, Valderramos JC, Vilcheze C, Siedner M, Tsai JH, Falkard B, Sidhu AB, Purcell LA, Gratraud P, Kremer L, Waters AP, Schiehser G, Jacobus DP, Janse CJ, Ager A, Jacobs WR, Jr., Sacchettini JC, Heussler V, Sinnis P, and Fidock DA. The fatty acid biosynthesis enzyme FabI plays a key role in the development of liverstage malarial parasites. Cell Host Microbe 4: 567-578, 2008.

179. Zamocky M, Furtmuller PG, and Obinger C. Evolution of catalases from bacteria to humans. Antioxid Redox Signal 10: 1527-1548, 2008.

180. Zamocky M, Furtmuller PG, and Obinger C. Evolution of structure and function of Class I peroxidases. Arch Biochem Biophys 500: 45-57, 2010.

181. Zhuang J, Reddi AR, Wang Z, Khodaverdian B, Hegg EL, and Gibney BR. Evaluating the roles of the heme a side chains in cytochrome $c$ oxidase using designed heme proteins. Biochemistry 45: 12530-12538, 2006.

Address correspondence to: Dr. Giel G. van Dooren

Research School of Biology Australian National University Canberra, ACT, 0200 Australia

E-mail: giel.vandooren@anu.edu.au

Prof. Geoffrey I. McFadden Plant Cell Biology Research Centre School of Botany University of Melbourne Parkville, Victoria 3010 Australia

E-mail: gim@unimelb.edu.au

Date of first submission to ARS Central, January 22, 2012; date of acceptance, February 8, 2012.

\begin{tabular}{|c|}
\hline 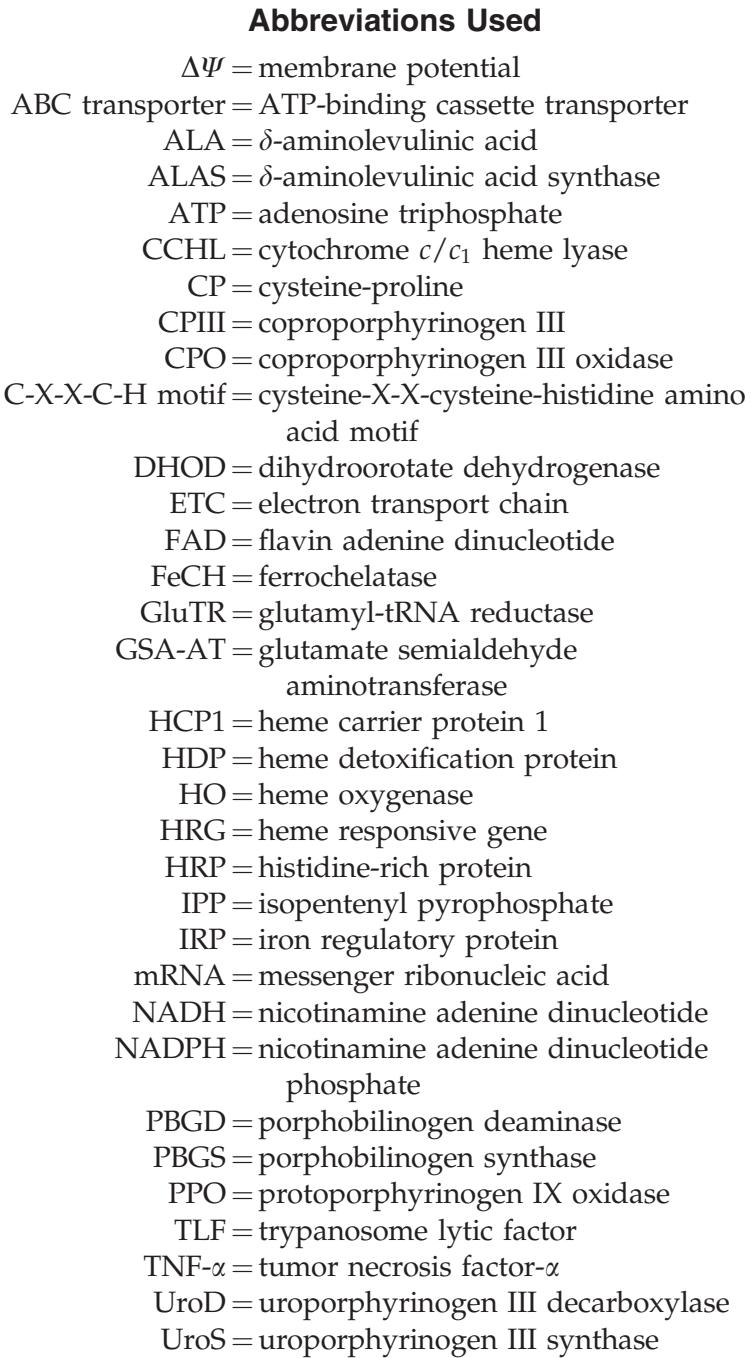 \\
\hline
\end{tabular}


This article has been cited by:

1. Michael Baureder, Lars HederstedtHeme Proteins in Lactic Acid Bacteria 62, 1-43. [CrossRef] 